\title{
Factives at hand: When presupposition mode affects motor response
}

\author{
Robert Reinecke ${ }^{1,2}$, Tatjana A. Nazir ${ }^{3}$, Sarah Carvallo ${ }^{2,4}$, and Jacques Jayez ${ }^{2}$
}

${ }^{1}$ FORS - Swiss Centre of Expertise in the Social Sciences

${ }^{2}$ Ecole Normale Supérieure de Lyon

${ }^{3}$ Univ. Lille, CNRS, UMR 9193 - SCALab - Sciences Cognitives et Sciences Affectives, F-59000 Lille, France

${ }^{4}$ Université de Franche-Comté

Author Note

This work was supported by the French National Agency for Research (CogHuLiCe ANR 16-CE28-0004) attributed to TN and SC, by a DAAD scholarship to RR, and by the French National Center for Scientific Research (CNRS).

Experiment 1 and 2 of the present article have been presented at the following conferences:

Reinecke, R., Nazir, T, Carvallo, S., \& Jayez, J. (2019, Nov 8). Factives at hand. Paper presented at Experimental Pragmatics Switzerland (Neuchâtel, Switzerland).

Reinecke, R., Nazir, T, Carvallo, S., \& Jayez, J. (2018, May 30 - June 1. Presuppositonal effects trigger context sensitivity of language-induced motor activity: A grip-force study. Paper presented at XPrag.it (Pavia, Italy).

Reinecke, R., Nazir, T, Carvallo, S., \& Jayez, J. (2018, March 15 - 17). Presuppositonal effects trigger context sensitivity of language-induced motor activity: A grip-force study. Poster presented at 31st Annual CUNY Sentence Processing Conference 2018 (Davis, CA, USA).

The data is available here: https://osf.io/jkbh3/?view_only=84b88ca56e7347b987b0d24099dec9e2 and was not preregistered.

Corresponding author: Robert Reinecke - robert.reinecke@ fors.unil.ch

FORS - Swiss Centre of Expertise in the Social Sciences - Bâtiment Géopolis, $5^{\text {th }}$ floor Reception desk, CH1050 Lausanne 


\section{ABSTRACT}

It is well-established that the processing of hand, mouth, and foot-related action terms can activate areas of the motor cortex that are involved in the planning and execution of the described actions. In the present study, the sensitivity of these motor-structures to language processes is exploited to test linguistic theories on information-layering. Human languages possess a variety of linguistic devices, so-called presupposition triggers, which allow us to convey background information without asserting it. A statement such as Marie stopped smoking presupposes, without asserting it, that Marie used to smoke. How such presupposed information is represented in the brain is not yet understood. Using a grip force sensor that allows capturing motor brain activity during language processing, we investigate effects of information-layering by comparing asserted information that are known to trigger motor activity (In the living room, Peter irons his shirt) with information embedded under a presuppositional factive verb construction (Louis knows that Peter irons his shirt; Experiment 1) and a non-factive verb construction (Louis believes that Peter irons his shirt; Experiment 2). Furthermore, we examine whether the projection behavior of a factive verb construction modulates grip force under negation (Louis does not know that Peter irons his shirt; Experiment 3). The data show that only the Presupposed Action verb in affirmative contexts (Experiment 1) triggers an increase in grip force comparable to the one of Asserted Action verbs, whereas the non-factive complement shows a weaker response (Experiment 2) and the projection structure does not trigger a grip force activation (Experiment 3). While the first two experiments seem to confirm the sensitivity of the grip force response to the construction of a plausible situation or event model, in which the motor action is represented as taking place, the third one raises the question of how robust this hypothesis is and how it can take the specificity of projection into account.

Keywords: language processing, presupposition, negation, language-induced motor activity 


\section{INTRODUCTION}

Human languages possess a variety of linguistic devices, so-called presupposition triggers, which allow us to convey background information without asserting it. Among these, we find factive verbs, like to know. When someone says Paul knows that Mary writes a letter, the verb know presupposes the truth of the complement clause that Mary writes a letter and asserts that Paul is certain that Mary writes a letter (Egré, 2008; Kiparsky \& Kiparsky, 1970). The former corresponds to the background information, the latter to the foreground or assertive information. In linguistics, presupposition is information which has been previously introduced or commonly believed, or at least presented as such (Stalnaker, 1974). After having been extensively scrutinized from a theoretical perspective (e.g. Beaver, 2001; Gazdar, 1979; Geurts, 1999; Heim, 1983; Karttunen, 1974; Stalnaker, 1974; Schlenker, 2008), presuppositions have been more recently investigated experimentally. The current experimental literature on presuppositions provides insights into the time course of their interpretation as well as into the cognitive costs associated with presupposition processing (e.g. Domaneschi, 2016; Schwarz, 2015).

This paper aims at deepening the understanding of the cognitive underpinnings of presupposition processing by monitoring sensori-motor activity that can accompany the processing of action words.

The relationship between language processing and activity in modality specific brain structure has received great attention within the field of cognitive neuroscience (see Kiefer \& Pulvermüller, 2012; Pulvermüller, 2005; Willems \& Casasanto, 2011 for a review) but its implications for linguistic theories have just started to be explored. In this paper, we address the question of whether presuppositional contexts modulate the sensori-motor activation elicited by action verbs. While hand-related action verbs in simple affirmative assertive sentences trigger a response in sensori-motor structures of the brain (e.g. Aziz-Zadeh et al., 2006; Hauk et al., 2004; Tettamanti et al., 2005), it has been shown that it is not always the case in other linguistic environments, such as negation or volitional verbs (want, desire, etc.), (e.g. Aravena et al., 2012, 2014; Zwaan et al., 2010; Papeo et al., 2016; Tettamanti et al., 2008). The question then naturally arises whether hand-related action verbs trigger a similar response when they are part of the presupposition. Answering this question is interesting from two perspectives. First, it would augment our knowledge of the array of contexts in which a sensori-motor response can 
be evoked. Second, it would contribute to a better understanding of the cognitive status of presuppositional information. In particular, if, as the descriptive and theoretical literature suggests, presuppositions are not the main piece of information in the linguistic message, it is possible that this secondary or peripheral status is reflected in a difference of impact on the sensori-motor system. In particular, the motor response observed with action verbs in simple assertions could be weaker when the same verbs convey presuppositions, that is subsidiary information.

In order to convey a more concrete sense of what is at stake, we proceed as follows in this introduction: First, we present a short overview of recent studies indicating the context-sensitivity of sensorimotor activation during language processing. Second, we introduce the linguistic phenomenon of presuppositions, focusing on the empirical observations which support their alleged non-central status. Finally, we give an overview of the experimental studies presented in the paper.

\subsection{Variations in sensori-motor cortex activation during language processing}

A large body of evidence shows that sensorimotor cortices can be recruited during action-related language processing, although differences exist in the interpretation given to this phenomenon (for a recent review see e.g., Cayol \& Nazir, 2020). Early studies highlighted that words that refer to actions performed with the arm, mouth and leg can activate areas of the motor cortex involved in the planning and execution of the described actions (e.g. Aziz-Zadeh et al., 2006; Hauk et al., 2004; Tettamanti et al., 2005) in a rapid and automatic manner (Pulvermüller et al., 2005). The observation of such language-induced "motor resonance" was initially taken to suggest that the elaboration of the meaning of these words is contingent on the recruitment of distributed networks of sensorimotor structures (e.g. Gallese \& Lakoff, 2005; Pulvermüller et al., 2005). However, these early findings have been challenged by more recent studies that question the automaticity of word-related sensorimotor activation. For example, the recruitment of modality-specific brain regions during action verb processing has been shown to vary as a function of the object of the action. Hence, Moody and Gennari (2010) demonstrated that for the same action verb, language induced activity in motor brain structures depends on the effort involved in manipulating a specific object. More specifically, the authors found that premotor cortex activation is strongest in a heavy object / high effort condition (The athlete is throw- 
ing the javelin), middle in a light object / low effort condition (The athlete is throwing the frisbee) and lowest in a no effort condition (The athlete noticed the frisbee).

Crucially, though, language-related sensori-motor activation is not only modulated by such extralinguistic context but appears also to be affected by the linguistic context which embeds the relevant action word. One of the first pieces of evidence that the excitability of motor brain structures depends on the linguistic context comes from studies which focus on the distinction between literal and nonliteral uses of language. Results from the study by Aziz-Zadeh et al.'s (2006), for instance, indicate that literal hand-, foot-, and mouth-related action verbs activate similar motor brain structures when actions of the respective type are observed, whereas their non-literal counterpart, in expressions such as chewing over the details, grasping the idea, and kicking off the year, did not elicit the same response. In accordance with this finding, Raposo et al. (2009) also highlight the context sensitivity of action verbs, that is, the fact that context is a crucial factor of how an action verb is processed. Their data indicate that isolated action verbs (e.g. grab) activate motor regions to a higher degree than action verbs in literal sentential contexts (e.g. The fruit cake was the last one so Claire grabbed it). In addition, the motor and premotor cortices are not activated when action verbs are presented in an idiomatic context (e.g. The job offer was a great chance so Claire grabbed it). Much evidence confirms the substantial difference of activation between the literal and idiomatic use of action verbs (Cacciari et al., 2011; Desai et al., 2013; Lauro et al., 2013; but see Boulenger et al., 2008; Boulenger et al., 2012 - for a detailed interpretation of their different findings see Willems \& Casasanto, 2011). Lauro et al. (2013) examine the difference between the literal use of action verbs and three different figurative meanings, i.e. metaphors, fictive action, and idioms. Their results point out that literal and idiomatic uses of action verbs appear to be endpoints of a motor brain activation continuum, that is, literal action verbs activate premotor brain areas, whereas action verbs that are part of an idiom do not. Metaphors like Paul throws his sadness away range between these two poles of the continuum. This intermediate status is typically explained by arguing that even if metaphors depict action simulations that are impossible to perform, the comprehension process relies on past body related experiences in order to correctly infer the metaphorical meaning (for a theoretical view see Gibbs et al., 2004; Gibbs, 2006). 
The linguistic modulation of sensori-motor activity is not limited to the literal/non-literal distinction as other linguistic factors have also been shown to be critical. Firstly, the same action word embedded in a negated sentence (I do not push the button) does not activate the brain's motor structures in the same way as in affirmative sentences (e.g. Aravena et al., 2012; Tettamanti et al., 2008). Furthermore, no language-induced motor activity is present when action words are embedded within a volitional context (Fiona wants to sign the contract) (Zwaan et al. 2010; Aravena et al., 2014). However, motor structures can be activated by a gapped verb, i.e. when the context sets up an expectation of an upcoming motor-related action such as in "John closes a juice bottle and Jim [ ] a lemonade bottle" (Claus, 2015). Aravena et al. (2014) even demonstrated that a novel word-form that has never been encountered before can activate motor brain structures when the linguistic context suggests a manual action (see also Zubicaray et al. (2013) for similar results with isolated, disyllabic nonwords containing endings with probabilistic cues predictive of verb status). Altogether, these studies highlight that contextual manipulations of lexical properties - interpretation of metaphors and idioms, the presence of a negation operator, a volitional or a gapped verb - have an impact on the involved brain structures $^{1}$.

Contextual manipulations that involve discourse properties also have an impact on the elicited sensori-motor activation. For instance, van Ackeren et al. (2012) showed that a sentence such as It is very hot here can be processed in different ways. In a context where this utterance can be interpreted as an indirect request of action - seeing a picture of a window (which triggers the indirect request open the window) - cortical motor areas are activated, whereas this is not the case when the utterance is not interpreted as an indirect request - seeing a picture of a desert (for related findings see also van Ackeren et al., 2016; Egorova et al., 2014). These findings provide the first evidence that sensori-motor activation is elicited even when the information is conveyed implicitly and must be inferentially derived in order to understand what is meant (an implicature in the sense of Grice, 1975). Van Ackeren et

\footnotetext{
${ }^{1}$ It is important to highlight once more that sensorimotor activation is not automatic, as pointed out by numerous findings (e.g. Tomasino \& Rumiati, 2013, for a meta-analysis regarding the neuroscientific evidence, see e.g., Watson, Cardillo, Ianni, \& Chatterjee, 2013). However, as recently proposed by Cayol \& Nazir (2020), the activation of modality-specific brain regions during language processing may not be necessary, but can aide to optimize simulations, in cases "in which the action/perception is 'veridical' and/or the 'linguistic focus' of the verbally depicted situation” (p. 14). Such a view is in line with Meteyard et al.'s (2012) theoretical review pointing out that the current scientific evidence is neither in favour for strongly embodied accounts nor disembodied ones.
} 
al.'s (2012) results highlight that discourse properties - such as the layering of information realized by the distinction between what is literally said and what is implicated - also drive sensori-motor activation.

In short, while there is little doubt that under certain contextual conditions language processing recruits sensorimotor structures of the brain, the function of this activity is yet to be specified. For a better understanding, it is therefore worth expanding these findings and examining further linguistic conditions that make use of motor brain structures in order to uncover the underlying mechanisms. We now turn to the phenomenon of linguistic presupposition.

\subsection{Presuppositions}

Linguistic presupposition is a type of information which is triggered by the presence of certain linguistic expressions (presupposition triggers) and is usually conveyed in discourse as part of the background of the conversation. A variety of distinct linguistic forms such as definite descriptions as in (1), change of state verbs as in (2), iterative adverbs as in (3), wh-question as in (4) and constructions like temporal clauses as in (5) trigger presuppositions (for an extensive list see Beaver, Geurts \& Denlinger, 2021; Levinson, 1983).

1. I have to pick up my sister at the airport.

I have a sister.

(Presupposition)

2. Peter stopped smoking.

Peter used to smoke.

(Presupposition)

3. Barack Obama was elected again.

Barack Obama was elected before. ( $\quad$ Presupposition)

4. When did Michael leave the house?

Michael left the house. $\quad$ (Presupposition)

5. Before Strawson was even born, Frege noticed presuppositions.

Somebody named Strawson was born. (Presupposition)

As can be seen from these examples, presupposition triggers are often used without even noticing it and are ubiquitous in discourse. In contrast to implicatures, which are heavily dependent on inference, 
the presuppositional layering is coded as a property of constructions. The presupposition triggers of interest in our study are factive verbs, which presuppose that their complement clause expresses a true proposition (Egré, 2008; Kiparsky \& Kiparsky, 1970). For instance, in (6) the factive verb know presupposes that Mary writes a letter (6b) and asserts that Paul is certain that Mary writes a letter (6a).

6. Paul knows that Mary writes a letter.

(6a) Paul is certain that Mary writes a letter. (At-issue content)

(6b) Mary writes a letter. (Presupposition)

It is important to note that the speaker is committed to the truth of the content she conveys by using a presupposition (Peters, 2016). ${ }^{2}$ Similarly, several authors, including for instance Geurts (1999) and Reboul (2017) note that presuppositions are not cancellable or defeasible, hence the oddness of a sentence like in (7), where the presupposition is negated.

7. Mary didn't write a letter and Paul knows that she wrote a letter.

In terms of speaker commitment, it seems that presuppositions are quite comparable to other components of information. As a result, at least for simple assertive sentences, presupposed and nonpresupposed content seem to be on a par. Must we conclude that these two types of content are really one single type and that, in examples like those of (1)-(5) above, they are just communicated in parallel, without any hierarchy? The linguistic literature on presuppositions has inventoried several phenomena which suggest otherwise.

(a) Presuppositions are typically part of the common ground, that is, the set of beliefs shared by the participants. In this line, presuppositions are not considered as the questions under discussion not at issue in the current linguistic terminology - since they are taken for granted and (presented as) admitted by the interlocutors (Ducrot, 1972; Stalnaker, 1974). As a result, presuppositions are considered to condition the appropriateness of an utterance. Using the sentence in (6) out of

\footnotetext{
${ }^{2}$ This does not entail that the speaker believes the presupposition. As pointed out by a reviewer, it is sufficient that the speaker accept the presupposition in the terms of Stalnaker (2002), that is, treat it as true, no matter whether she believes it or not. However, the speaker remains committed to the truth of the content conveyed by the presupposition. In some cases, this content does not correspond to the literal meaning. For instance, recycling an example of Stalnaker, two speakers could use deliberately a description that they know to be inappropriate, just because they also know that it has been used to successfully identify an entity. For instance, they could agree to designate a man drinking sprinkling water by the man with a martini because they have believed at some point that the man in question was actually drinking martini. In such a case, they are not committed to the truth of the literal description but to the truth of a related, but different, description: the man that we designated by the property of drinking a martini.
} 
the blue might be felt as uncooperative because the presupposition (6b) is not yet part of the common ground. Content that is not yet part of the common ground but presented as such may result into accommodation, that is, the process by which the hearer accepts the presuppositional content as true and includes it into her set of beliefs (Heim, 1983; Lewis, 1979).

(b) Presuppositions do not always provide natural answers to questions. If one asks Is Paul coming to the party? and someone else answers by I'm coming too, meaning that Paul is coming, the answer sounds odd since the desired answer to the question is provided by the presupposed content and not by the asserted content.

(c) Presuppositions obey restrictions with respect to discourse continuations, that is, the so-called linking law (loi d'enchaînement) by Ducrot (1972). Paul stopped smoking because it's bad for health involves the at-issue content as the continuation and makes perfect sense. In contrast, Paul stopped smoking because he likes that cannot mean that Paul does not smoke and that he had been smoking because he liked that (linking to the presupposition only is not an option in a discourse continuation).

(d) Further evidence of the difference between asserted and presupposed content comes from the so-called projection property of presuppositions: When an operator that suspends or shifts the truth value is applied to a sentence containing a presupposition trigger, it affects the at-issue content but, in general, not the presupposition. For instance, the negation of the factive verb in (8), denies that Paul is certain that Mary writes a letter, that is, it alters the meaning of the atissue (asserted) content in comparison to the sentence in (6). However, the presupposition remains untouched, that is, the negated sentence still presupposes that Mary writes a letter, exactly as the positive sentence in (6) does. This and similar observations on questions as in (9) and on modal verbs as in (10) correspond to what linguists have called presupposition projection (see for instance Chierchia \& McConnell-Ginet, 1990; Ducrot, 1972; Geurts, 1999; Heim, 1983).

8. Paul does not know that Mary writes a letter.

9. Does Paul know that Mary writes a letter?

10. Paul might know that Mary writes a letter. 
Given the above observations, and in spite of numerous variations, philosophers and linguists have converged toward a common intuition: in most cases, the presupposed content is, in some sense, more marginal or peripheral than the at-issue content. The difference between the two types of content is not so much truth-conditional as communicative. While the at-issue content addresses directly communication topics, presuppositions convey secondary aspects, which are not directly relevant to these topics. If this intuition is at least partially correct, one might hope to detect experimental traces of the difference, and there is indeed evidence in this direction (e.g., see Schwarz, 2015, 2016 for a detailed discussion).

A line of research concerns the previously mentioned topic of accommodation, i.e., accepting the presuppositional content, that has not been part of the common ground prior utterance, as true. Recent experimental investigations indicate that various settings where the presupposed content is not present in the context and has to be inferred by the hearer incurs extra processing costs (EEG study by Domaneschi et al., 2018; self-paced reading study by Tiemann et al., 2011; Domaneschi \& Di Paola, 2017; Reinecke, Di Paola, Domaneschi \& Fossard, resubmitted; eye-tracking study by Tiemann \& Schwarz, 2012). However, there is also evidence that accommodated presuppositions are integrated rapidly (behavioral results of Domaneschi et al., 2018, Domaneschi \& Di Paola, 2017; Reinecke et al., resubmitted, EEG study of Masia et al., 2017, eye-tracking studies of Romoli et al., 2015; Schwarz, 2014). Another topic is projection. Work by Chemla and Bott (2013) and Romoli and Schwarz (2016) show that the projective interpretation is preferred and/or derived faster than the non-projective one ${ }^{3}$.

Our own research is aimed at investigating the cognitive correlates of presupposition processing in a complementary perspective. It is motivated by the apparently special status of presupposed information. In particular, it is possible that, being in some sense less central or only parallel to the discourse topic, presuppositions elicit a different motor activation than at-issue content.

\subsection{The Present Research}

\footnotetext{
${ }^{3}$ To clarify, the projective interpretation of Paul doesn't know that Mary is coming makes the proposition that Mary is coming true. If the interpretation is non-projective it makes the same proposition indeterminate or false.
} 
In the 2-dimensional context of descriptive/experimental investigations on presupposition and studies on motor resonance during language processing, the phenomenon of presupposition stands out as special in four respects.

(1) As mentioned above, motor resonance during the processing of action verbs is not observed within sentential environments that involve negation (Aravena et al., 2012; Tettamanti et al., 2008; Papeo et al., 2016) or volitional verbs (Aravena et al., 2014; Zwaan, et al., 2010). A straightforward interpretation of these observations is that the discourse or situation model (cf. Zwaan and Radvansky, 1998; Radvansky and Zwaan, 2014) constructed by listeners in such cases does not include the event described by the action expression and, consequently, is not associated with a motor response (see Aravena et al., 2014; Cayol and Nazir, 2020). Sensorimotor activation is triggered when the action of the corresponding verbal group is presented as actually taking place. Taylor and Zwaan (2008) called this the Linguistic Focus Hypothesis ${ }^{4}$. In this line, saying that Paul does not throw the ball, for instance, leaves no room for an event of throwing a ball in the situation model. If presuppositions are presented by the speaker as true, they are part of the depicted situation and should therefore trigger a motor response whenever a motor action is involved (e.g. the word writes in a factive verb construction as in (12)). Contrariwise, if presuppositions are peripheral information, one could also expect that they will not elicit the same response as assertions. Our study will shed light on how presuppositions are processed in the motor brain structures.

(2) Most of the currently available observations and experiments on presuppositions concern linguistic operators or contexts (e.g., for aspectual verbs and definite descriptions, Domaneschi et al., 2018; for wieder (again), Schwarz \& Tiemann, 2012, for processing factives versus nonfactives, Shetreet et al., 2019). Operators like negation or interrogation reveal projection properties, while contexts are relevant to the discourse-based properties of presupposition triggers, like accommodation. In contrast, we have only scarce information (mostly syntactic) about

\footnotetext{
${ }^{4}$ It is important to note that Zwaan and Taylor's (2008) use of the term focus is different from what linguists call 'focus'. For Zwaan and Taylor, focus is linked to an action that takes place at the current time point.
} 
possibly intrinsic, that is context-independent, properties of triggers. Does a presupposition in a simple decontextualized assertive sentence have cognitive properties that distinguish it from an assertion or are such properties visible only in richer environments (embedding operators, or the presence of an explicit context)? Given that a large part of the literature on motor resonance focuses on isolated words or simple sentences, it is necessary to design experiments that allow testing these intrinsic properties of presupposition triggers.

(3) Studying presupposition triggers raises the question of which trigger(s) to use in experiments. Factive verb constructions are a particularly interesting starting point from different aspects. First, with factives, the asserted and presupposed contents are both explicitly expressed at the sentential level, which is a unique characteristic when compared to other presupposition triggers such as so-called aspectual verbs ${ }^{5}$. This explicitness allows one to directly compare the presupposed content of Paul knows that Mary writes a letter to an assertion such as Mary writes a letter without making an effort to infer the implicit presupposed content as with other presupposition triggers. Second, it was shown that, in otherwise totally parallel clausal complement constructions, factive verbs (know-type) presuppose the truth of its complement clause, whereas non-factive verbs (believe-type) do not commit one to the veracity of their complement clause. Therefore, it makes sense to investigate whether this distinction also has a cognitive motor resonance counterpart.

(4) In contrast to factive verbs, non-factive verb constructions as in (11) impose no constraint on the truth-value of the embedded that-clause (for an overview on factive and non-factive mental states see Nagel, 2017). As noted earlier, the sentences in (12) and (14) presuppose the truth of the complement, whereas its truthfulness in (11) and (13) may depend, among other factors, on the reliability of Paul (Nagel, 2017).

11. Paul thinks that Mary writes a letter.

\footnotetext{
${ }^{5}$ The term aspectual in this context denotes change of state or transition verbs like begin, stop, resume, interrupt, continue, etc. Their presupposed content is entailed by default. The sentence Mary stopped smoking asserts explicitly that Mary does not smoke and presupposes that Mary used to smoke.
} 
12. Paul knows that Mary writes a letter.

13. Paul does not think that Mary writes a letter.

14. Paul does not know that Mary writes a letter.

On these grounds, we present three experiments, in which a grip force sensor is used to monitor variations of grip force between thumb and index finger after the onset of a critical word (a hand-related action verb in our case). A word-induced increase of grip-force can be interpreted as an incomplete inhibition that arises from primary motor cortex activity (Aravena et al., 2012; 2014; Jeannerod, 1994). Previous research has shown that grip force plays an essential role with respect to the predictive and reactive control of the capacity to hold and lift objects (for a review see Delevoye-Turrell \& Wing, 2005). Healthy adults, whose anticipatory predictive and reactive control is intact, easily adjust grip force to the mass and texture of an object (Johansson et al., 1984). Crucially, previous studies have demonstrated the link between grip force and motor brain activity: the primary, premotor, supplementary and cingulate cortical motor areas as well as the cerebellum play a crucial role when information is sent via spinal motor neurons to the finger muscles (e.g., Dum \& Strick, 1991; Lemon, 1993; Ward et al., 2007). Moreover, recent neurophysiological evidence using the fMRI technique showed that when gently holding an object (in the right hand), grip forces activate the left primary sensorimotor cortex, the ventral premotor cortex and the left posterior parietal cortex (Kuhtz-Buschbeck et al., 2001). By investigating grip force in a healthy adult population, it has been demonstrated that subtle grip force variations can be observed during language processing depending on the action status. When comparing action verbs and non-action related nouns, Frak et al. (2010) found that grip force variation increased for the former but not for the latter. This finding was extended to verbs by Aravena et al. $(2012,2014)$ and Nazir et al. (2017), with a direct comparison of action and non-action verbs.

Grip-force variation is typically measured while participants actively listen to auditory stimuli. Here, it is very important to stress that participants do not manipulate the sensor in relation to anything that concerns the experimental task. The sensor is not a "response button". Participants are just requested to hold the sensor with a pre-specified constant force. Once this force is adjusted, the sensor is no longer of interest to the participant. It just continuously indicates fluctuation of motor brain activity that spills over from the motor cortex to the muscles, similar to what an EEG electrode would do at the 
surface of the scalp. Hence, like for variations of brain potentials measured with an EEG electrode, systematic variations of grip force recorded at the tip of the fingers can be attributed to the processing of the stimuli to which the recorded signal is time-locked. Moreover, the source of the signal can be localized to motor structure of the brains. Using this tool, the following three research questions were addressed:

(RQ1): Does the presupposed (action-related) content of factive verb constructions elicit an increase in grip force?

The first experiment addresses the issue whether a piece of information which is (i) presented as true but (ii) syntactically marked as backgrounded activates motor brain structures. To do so we will compare the action-related content of an assertion to that of a factive complement. As noted above, the hybrid status of presuppositions (they are true but secondary) fosters doubt about which prediction is a priori the most plausible. Presuppositions are part of the situation model; however, their marginal status compared to an assertion may impact the processing in motor brain structures.

(RQ2): Does the action-related content of non-factive verb constructions elicit an increase in grip force?

The second experiment directly compares the action-related content of an assertion to the nonfactive complement. The a priori plausible predictions depend on the results of the first experiment. If the presupposition of factive verbs has a sensori-motor impact in virtue of being true, it is expected that this impact is weaker or absent with non-factive verbs, since the truth of the embedded clause is not guaranteed.

(RQ3): Does the presupposed (action-related) content of negative factive verb constructions elicit an increase in grip force?

The third experiment addresses the projection phenomenon of factive verb constructions. Again, if Experiment 1 provides evidence for some sensori-motor activation due to the truth of 
the presupposition, it is expected that a projective reading (i.e. one where the presupposition is considered as true) is preferred in projective environments, thus giving rise to an increase of motor activation comparable to that observed in Experiment 1.

\section{METHOD}

The present study was approved by the Ethical Committee CPP (Comité de Protection des Personnes)

Sud-Est II in Lyon, France. In the following we will describe the general method that applies to all three experiments. Further details are provided in the respective method sections of the individual experiments.

\section{Participants}

Participants were undergraduate students and native speakers of French. They had normal or corrected to normal vision, no history of neurological or psychiatric disorders, and were right-handed as attested by the Edinburgh Handedness questionnaire. All participants gave an informed written consent and were informed that they could end the experiment at any moment. They were paid for their participation.

\section{Stimuli}

All stimuli sentences contained hand-related action verbs involving grip actions ${ }^{6}$, except the control sentences, which contained non-action verbs such as souhaiter $(\text { wish })^{7}$. Sentence specific characteris-

\footnotetext{
${ }^{6}$ As pointed out by a reviewer, the hand-relatedness of the experimental stimuli does not guarantee that the observable effects are limited to the hand. There is indeed no strong specificity of the motor activation in relation to the body part involved in an action. For instance, Boulenger et al. (2006) showed that, in a reaching-andgrasping task, hand-related and leg or mouth-related action verbs affected the movement kinematics. However, the hand-related action verbs had the strongest effect. Other studies suggest that there is at least a partial somatotopicality of the action lexicon (see references in Boulenger et al., 2006, pp. 1607-1608). In the context of the present paper, it is not crucial to decide whether hand-related action verbs trigger a (partially) specific activation or a more general one, since what we investigate is whether motor activation, whatever regions it concerns, that might be trigged by theses action words is modulated by the linguistic status of certain clauses.

${ }^{7}$ We use the term non-action throughout this paper to refer to the absence of actions of the muscles. Hence, while dreaming is an action it is considered as a "non-action" because it does not involve motor muscles.
} 
tics are detailed in the method sections of the individual experiments. All stimuli are provided in the Supplementary Material ${ }^{8}$.

\section{Measures and pre-tests}

The hand-related action verbs were selected in two steps. First, 20 participants rated a list of 120 handrelated action verbs as to the likelihood that the verb refers to a manual action, using a 5-point Likert scale: (1) never, (2) rarely, (3) sometimes, (4) often, and (5) always. Second, for the 66 verbs that received a rating of at least (4), another group of 58 participants was requested to complete a list of sentences containing the selected verbs (e.g Ines ties ). We randomly divided the 66 verbs into two lists, each containing 33 verbs. Participants were randomly assigned to one of the two lists. Sentences which met the following criteria were included in the study: (1) Sentence completion was related to a manual activity and (2) the mean cloze probability for the chosen continuation was at least $25 \%$. A final list of 37 sentences served as stimuli for the grip force study.

\section{Recording}

The stimuli for all the experiments were recorded in a sound booth by the same female speaker with a Roland Edirol R-09, at a $48 \mathrm{KHz}$ sampling rate with 24-bit digitalization. Special care was taken that the speaker maintained a relatively flat prosody and avoided any loudness or pitch variation on the critical words (i.e. the verb and the noun).

\section{Equipment and data acquisition}

Two distinct computers were used for data recording and stimulus presentation, in order to ensure synchronization between audio files and grip-force measurements (estimated error $<5$ milliseconds). The first computer read the playlist of the pseudo-randomized stimuli. The second computer recorded the incoming force signals from the load cell at a high sampling rate of $1000 \mathrm{~Hz}$. To measure the activity of the hand muscles, a 6-axis load cell of $68 \mathrm{~g}$ was used (ATI Industrial Automation, USA, see Fig-

\footnotetext{
${ }^{8}$ All stimuli, participants' collected data, and figures can also be found here: https://osf.io/jkbh3/?view_only=84b88ca56e7347b987b0d24099dec9e2
} 
ure 1). Like in previous studies (e.g. Frak et al., 2010; Aravena et al., 2012;2014; Nazir et al., 2017), only the three main forces were recorded: the longitudinal (Fx,), radial (Fy) and compression forces (Fz), respectively (Figure 1B).

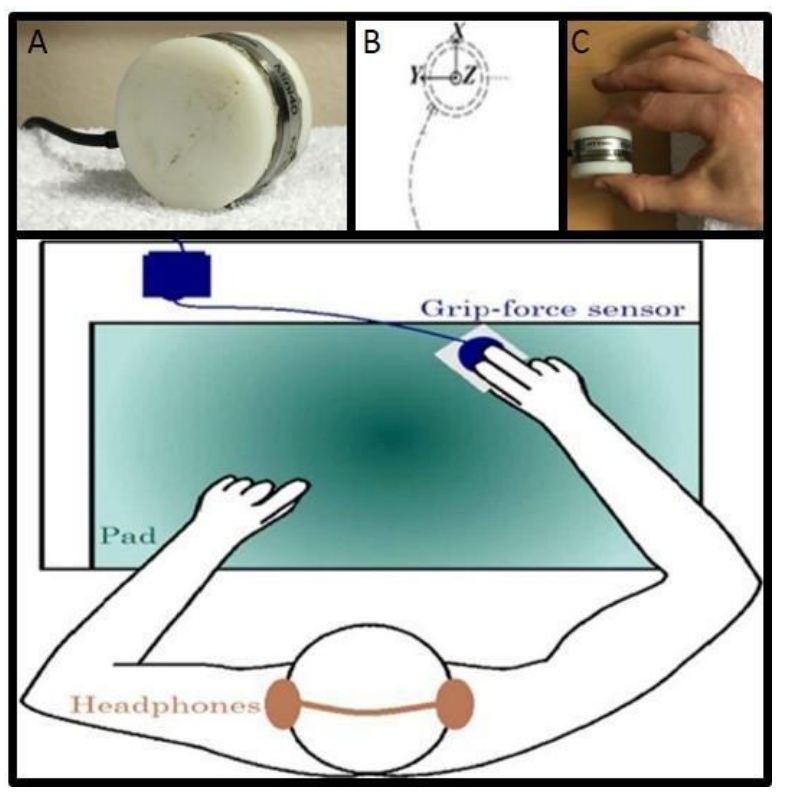

Figure 1. Experimental Material and Settings
(A) A standalone 6-axis load cell of $68 \mathrm{~g}$ was used (ATI Industrial Automation, USA). (B) The directions of the recorded forces: longitudinal (Fx), radial (Fy), and compression (Fz). (C) Participants held the grip-force sensor with their right thumb and index. Their wrist was placed on a 15 cm high box. Bottom panel: Participants wore headphones and were comfortably seated behind a desk on which a pad was placed. They were asked to rest their arms on the pad when holding the sensor.

\section{Procedure}

Participants wore headphones and were comfortably seated behind a desk on which a $15 \mathrm{~cm}$ high box was placed. They were asked to rest their right wrist on the box. Their hand was detached from the box, that is, it was free-standing and not in contact with the table when participants held the grip-force sensor with their right hand (see Figure 1C). The experimenter demonstrated the correct way to hold the grip force sensor and participants were requested to hold the cell with a constant force, measured as 1.5 Newton $(\mathrm{N})$. The thumb and index finger remained on the load cell during each block.

The experiment started with a training session of two blocks (in total, 21 stimuli), in which instructions about the experiment were given. In this session, the participants got familiarized with the task and had the opportunity to ask any question they found relevant. When they felt ready, the experiment started. Participants had to listen to 111 stimuli, distributed into 10 blocks, 9 blocks of 11 stimuli and a final block of 12. In order to avoid muscular fatigue, a 30-second pause occurred between two consecutive blocks, but the participants could ask for more if they judged that they needed more time to relax. At the beginning of each block, they had to control their initial grip force and adjust it to $1.5 \mathrm{~N}$, using 
the screen to monitor their performance. The experimenter informed the participant and started the auditory presentation as soon as the mentioned grip force level was met, and no fluctuations occurred. Participants kept their eyes closed for the duration of each block. At the end of each block, they put down the cell and a question with respect to the Action/Non-Action related verb appeared on the screen in front of them, which had to be answered by using the left ("yes") or right ("no") button of the mouse. The question was always of the form Did someone VP? For instance, after a block containing Mary ties her shoes, a participant might have to answer a question like Did someone tie her shoes? or Did someone clean her shoes? There was only one question per block, but participant could not determine in advance which action or object it was going to concern. The question scenario had been made as clear as possible to the participants in the training phase.

The total length of each experiment was approximately $25 \mathrm{~min}$. Participants were debriefed at the end of the experiment.

\section{Data handling and analysis}

Data processing and visualization were carried out in $R$ (R Core Team, 2019) using a number of specialized libraries, most notably stats (R Core Team, 2019), lme4 (Bates, Maechler, Bolker \& Walker, 2015), forcats (Wickham, 2019) and ggplot2 (Wickham, 2016).

Filtering, segmentation, and baseline correction. Prior to data analysis, each signal component was pre-treated in order to eliminate the regular electro-magnetic oscillations of the cell and keeping only the visually smooth trend of the signal. We used the function loess implemented in basic R. A visual trial-and-error procedure led to an interval of 0.15 , meaning that $15 \%$ of all the points were kept around each value to estimate the regression line. Finally, a baseline correction was performed from -300 to $0 \mathrm{~ms}$ prior to target onset. This correction was implemented because of a possible global change in grip-force during the session $(\approx 25$ min per participant), and because we were only interested in grip-force changes. Thus, we adjusted the post-stimulus values by subtracting the baseline values from all of the values in the epoch. Given that the participants were asked to hold the grip-force sensor throughout the experiment, a 'negative' grip-force refers to a lesser grip-force and not to the absence of grip-force, which is impossible in this context (the cell would just fall). 
Only $F z$ (compression force) was included in the analysis because this parameter was determined to be the most accurate indicator of prehensile grip-force (e.g. Frak et al., 2010). Using the Praat software (Boersma \& Weenink, 2019), the $F z$ signals were segmented offline. The temporal distance between the verb and the noun phrase varies across stimuli. A preliminary visual inspection suggested that, on average, the noticeable effects occur in the 300-1000 ms time interval after verb onset (for very similar time windows, see also Aravena et al., 2012; 2014).

Elimination of outliers. Prior to the statistical analysis, we inspected the average time- $F z$ plots for each participant in order to detect negative drifts, that is, a progressive decrease in the grip force amplitude during the first $1000 \mathrm{~ms}$ after verb onset. An example of a participant with a negative drift is given in Figure 2 (participant 16 of Experiment 3). Such drifts indicate that the participant did not hold the cell with sufficient constant pressure, due to incapacity, inattention or fatigue. The participants presenting negative drifts were therefore excluded from the analysis. Following the filtering options of Aravena et al. $(2012,2014)$, we also eliminated individual trials that showed data points above $200 \mathrm{mN}$ or below $150 \mathrm{mN}$. To detect such points, we chose a relatively large time window starting from verb onset to 500 ms after noun onset. All the final data sets are provided in the Supplementary Material.

Verb Mean (-300-1000ms) for participant 16

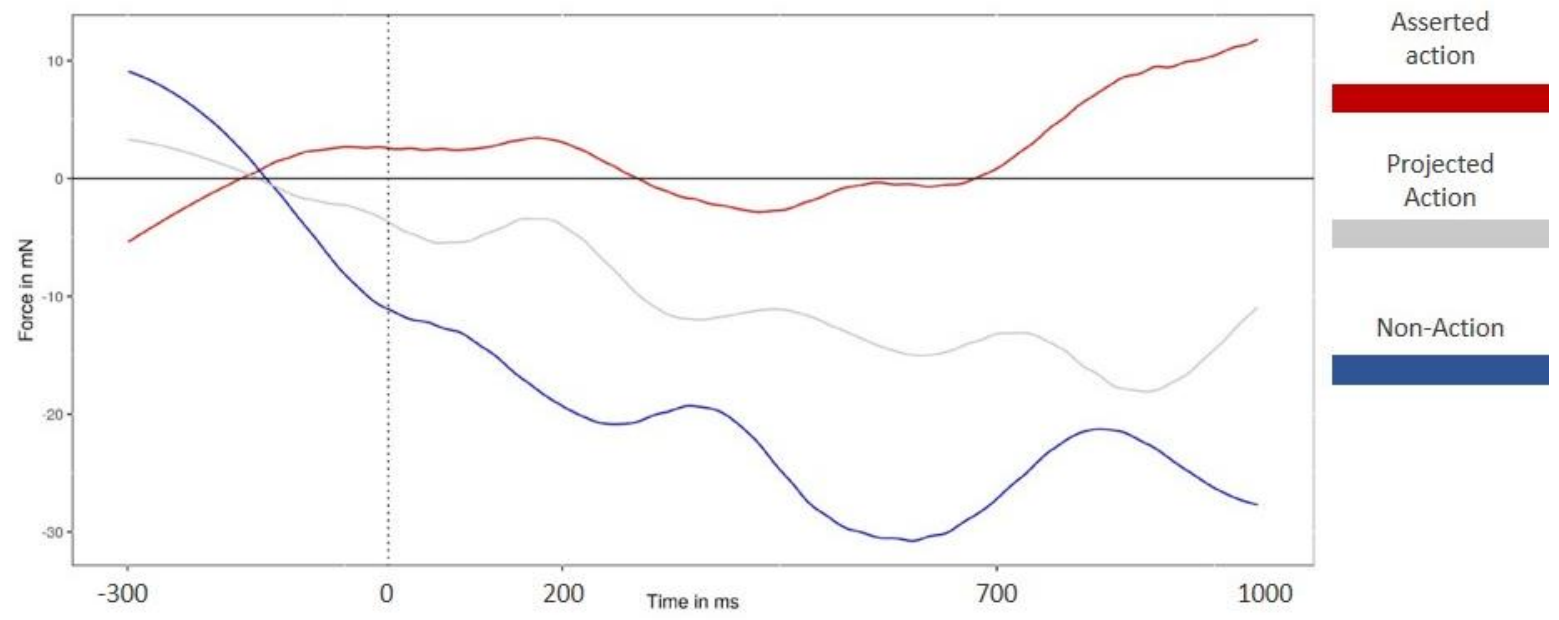

Figure 2. An example of negative drifts that results in a progressive decrease in grip force within the first $1000 \mathrm{~ms}$ after the onset of the critical word. Zero is the onset of the verb; baseline correction was applied over the $300 \mathrm{~ms}$ interval prior to verb onset. 
Statistical analysis. Inspection of the individual data evidences a large variability between participants, which makes the prospect of a well-defined non-linear model unrealistic. For our statistical analysis we therefore resorted to a non-parametric analysis. For each time window under consideration, and for each participant and item we determined the respective numbers of data points with a positive grip force value and data points with a negative or null grip force value. We then calculated the difference between the number of positive and negative/null incidences. For each participant, we averaged these differences over items of the same experimental condition. A Wilcoxon paired test was then used to compare two experimental conditions. Table 1 schematically indicates this procedure.

\section{Table 1.}

Structure of the Wilcoxon paired test for asserted vs. presupposed action in Experiment 1

\begin{tabular}{|c|c|c|c|c|}
\hline \multirow{3}{*}{$\begin{array}{l}\text { Participant } \\
1\end{array}$} & \multirow{3}{*}{$\begin{array}{l}\text { Averages of } \\
\text { differences }\end{array}$} & Asserted action & Presupposed action & \\
\hline & & $\begin{array}{c}\text { Item 1: } \\
\mathrm{nb} \text { of data points }>0 \\
\text { minus } \\
\mathrm{nb} \text { of data points } \leq 0\end{array}$ & $\begin{array}{c}\text { Item 1: } \\
\mathrm{nb} \text { of data points }>0 \\
\text { minus } \\
\mathrm{nb} \text { of data points } \leq 0\end{array}$ & \multirow{2}{*}{$\begin{array}{l}\text { Averages of } \\
\text { differences }\end{array}$} \\
\hline & & $\begin{array}{c}\text { Item } \mathrm{n}: \\
\mathrm{nb} \text { of data points }>0 \\
\text { minus } \\
\mathrm{nb} \text { of data points } \leq 0\end{array}$ & $\begin{array}{c}\text { Item } \mathrm{n}: \\
\mathrm{nb} \text { of data points }>0 \\
\text { minus } \\
\mathrm{nb} \text { of data points } \leq 0\end{array}$ & \\
\hline$\ldots$ & & $\ldots$ & $\ldots$ & \\
\hline $\begin{array}{l}\text { Participant } \\
\mathrm{n}\end{array}$ & $\begin{array}{l}\text { Averages of } \\
\text { differences }\end{array}$ & $\ldots$ & $\ldots$ & $\begin{array}{l}\text { Averages of } \\
\text { differences }\end{array}$ \\
\hline
\end{tabular}

Time window for the analysis. The size of the time windows to be analyzed was determined by taking into account the results of previous published experiments with a similar paradigm (Aravena 2012, 2014) and by considering the fact that our participants showed a relatively later increase in grip force. We therefore defined a fixed window of $300 \mathrm{~ms}$ between 600 and $900 \mathrm{~ms}$ after verb onset as critical time window and report data from adjacent temporal regions for comparison. We imposed two criteria: (1) the existence of an effect had to be determined on the basis of the 600-900 ms window, (2) the nonexistence of a difference between conditions had to be determined on the basis of the whole region from verb onset to $1200 \mathrm{~ms}$ (4 successive slices of $300 \mathrm{~ms}$ after verb onset). Any intermediate situation was categorized as inconclusive and the interpretative options it supports are discussed in the text.

\section{EXPERIMENTS}

\subsection{Experiment 1: Factivity}




\section{Method}

\section{Participants}

30 participants ( 25 women, $18-32$ years old; $\left.M_{\text {age }}=21.7, S D_{\text {age }}=1.55\right)$ participated in this study. All were right-handed $\left(M_{\text {laterality }}=.83 ; S D_{\text {laterality }}=.165 ;\right.$ cf. Oldfield, 1971$)$.

\section{Stimuli}

A total of 111 French sentences served as stimuli. 37 target hand-related action verbs were used. 8 distinct French factive verbs were used with respect to the factive stimuli: voir (to see, 5 times), s'apercevoir (to realize, 3 times), entendre (to hear, 5 times), réaliser (to realize, 6 times), remarquer (to notice, 6 times), observer (to observe, 5 times), se rendre compte (to realize, 2 times), and savoir (to know, 5 times). In addition, 37 sentences containing asserted non-action verbs served as control (see Aravena et al., 2012; 2014; Frak et al., 2010; Nazir et al., 2017). The action verbs and asserted non-action verbs were controlled for number of letters and number of syllables (New, Pallier, Ferrand, \& Matsos, 2001). Three examples of experimental stimuli are provided in Table 2.

Table 2.

Example of stimuli used in Experiment 1 and their approximate English translation

\begin{tabular}{|c|c|c|}
\hline Condition & Sample stimulus & $\begin{array}{l}\text { English approximate transla- } \\
\text { tion }\end{array}$ \\
\hline Asserted Action & $\begin{array}{l}\text { Avant de partir, Ines lace ses } \\
\text { chaussures. }\end{array}$ & $\begin{array}{l}\text { Before leaving, Ines ties her } \\
\text { shoes. }\end{array}$ \\
\hline Presupposed Action & $\begin{array}{l}\text { Daniel voit qu'Anne lace ses } \\
\text { chaussures. }\end{array}$ & $\begin{array}{l}\text { Daniel sees that Anne ties her } \\
\text { shoes. }\end{array}$ \\
\hline Non-Action & $\begin{array}{l}\text { Pour le dîner, Pierre souhaite } \\
\text { du poulet. }\end{array}$ & $\begin{array}{l}\text { For dinner, Peter would like } \\
\text { chicken. }\end{array}$ \\
\hline
\end{tabular}

All critical verbs were in the present tense and in the singular third person. Action verbs always appeared in the fifth position of the sentence. Non-action verbs appeared in the fifth position in 33 sentences, in the sixth position in 3 sentences and in the fourth position in 1 sentence. The onset of the target verb and the total duration of the sentence was determined using PRAAT. The onsets of the critical verb and noun for the Asserted Action condition (Before leaving, Ines ties her shoes) were on average $1406 \mathrm{~ms}(S D=205 \mathrm{~ms})$ and $1882 \mathrm{~ms}(S D=239 \mathrm{~ms})$ after the beginning of the sentence; for the Presupposed Action (Daniel sees that Anne ties her shoes.), they were on average $1255 \mathrm{~ms}(S D=160 \mathrm{~ms})$ 
and $1676 \mathrm{~ms}(S D=193 \mathrm{~ms})$; for the Non-Action condition (For dinner, Peter would like chicken.) they were $1257 \mathrm{~ms}(S D=183 \mathrm{~ms})$ and $1734 \mathrm{~ms}(S D=218 \mathrm{~ms})$.

\section{Design}

The order of the three conditions was pseudo-randomized. No more than two items of the same category appeared consecutively. To control for order effects, we independently generated random orderings for each participant. The 111 sentences were divided into 10 blocks. The first 9 blocks contained 11 sentences, the last one 12 sentences. At the end of each block there was one question of the form Did someone VP, for instance, after a block containing Mary tied her shoes, the following question appeared at the end of the block Did someone tie her shoes? (expected answer = yes) or Did someone clean her shoes? $($ expected answer $=$ no). The participant had no way to determine in advance which action was involved. The amount of yes/no questions was balanced, that is, a participant answered either 5 yes and 6 no question or 6 yes and 5 no questions. Response accuracy to the comprehension questions was not further considered in our analyses as it simply serves to motivate participants to stay attentive. However, participants with less than 6 correct answers were considered inattentive and were excluded from the analyses of the grip force data.

\section{Data Analysis}

5 participants were removed because of negative drifts $(3,10,12,15,19)$, one of them also scored low (3 correct answers) in the accuracy to the comprehension questions. Average response accuracy for the remaining participants was $7(S D=1.46)$. Finally, a total of 17 items with a grip force intensity below $-150 \mathrm{mN}$ or above $200 \mathrm{mN}$ were eliminated (6 for Asserted Action, 3 for Presupposed Action and 8 for Non-Action).

\section{Results}

The averaged grip force amplitude for the three experimental conditions are depicted in Figure 3. 


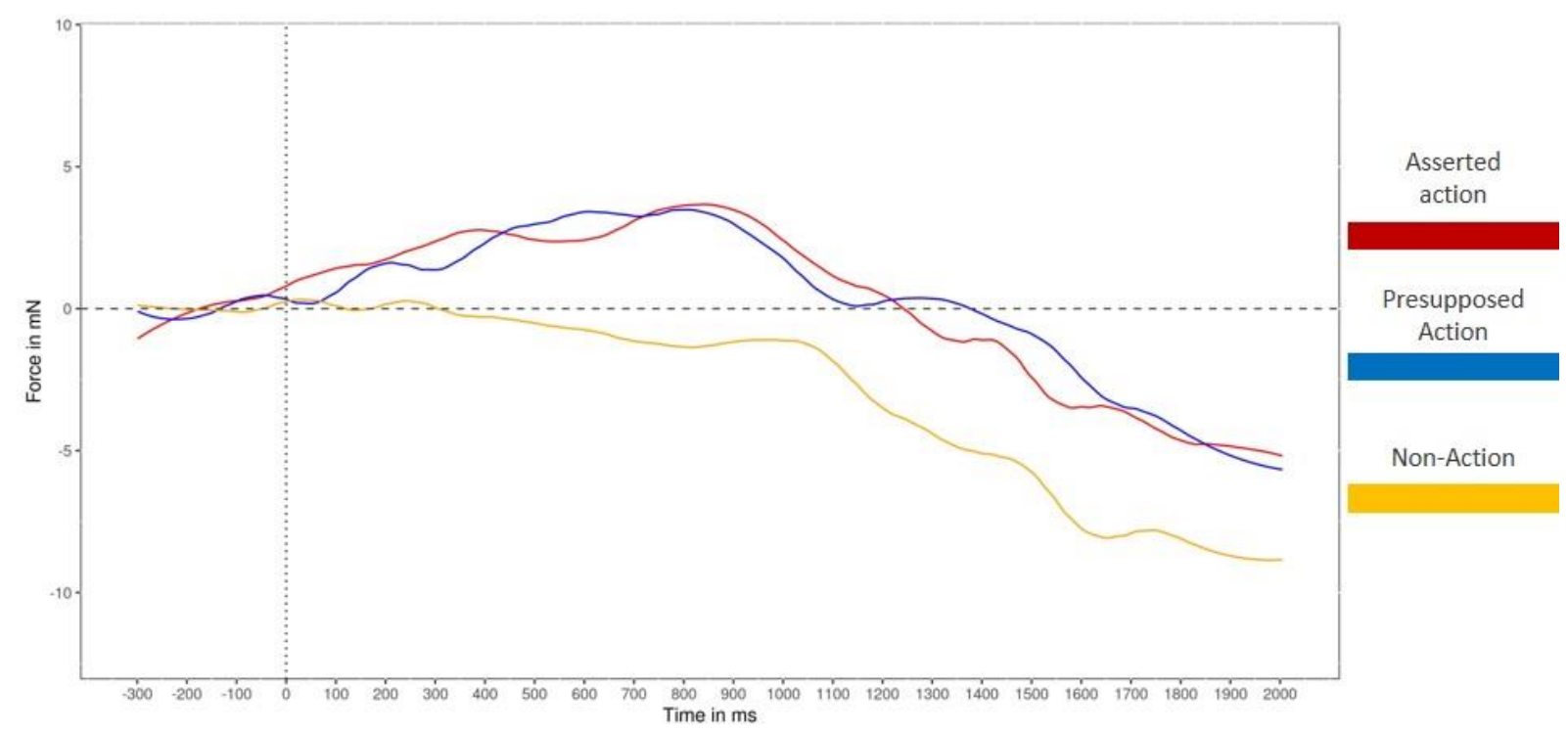

Figure 3. Results Experiment 1 - Modulation of grip force amplitude in the three experimental conditions as a function of time after the onset of the target word. Zero is the onset of the verb; baseline correction was applied over the $300 \mathrm{~ms}$ interval prior to verb onset.

The plot suggests that the Non-Action condition has lower values than the Asserted Action and Presupposed Action conditions and that the latter two are not very different. The results of the statistical analyses in Table 3 indicate significant differences in the critical time window (600-900 ms post stimulus onset) for the Asserted Action vs. Non-Action conditions and for the Presupposed Action vs. Non-Action conditions. Asserted Action do not differ from Presupposed Action in any of the time windows. Figure 4 summarizes the results in terms of inverted $\mathrm{p}$ values.

\section{Table 3.}

$P$ values for Experiment 1. $*=p<.05 . A A=$ Asserted Action; $P S P A=$ Presupposed Action; NA= NonAction.

\begin{tabular}{|c|c|l|}
\hline Window & Comparison & \multicolumn{1}{|c|}{ WT } \\
\hline \multirow{3}{*}{$1-300$} & AA vs. PSPA & -1 \\
\cline { 2 - 3 } & AA vs. NA & 0.4108 \\
\cline { 2 - 3 } & PSPA vs. NA & 0.5077 \\
\hline \multirow{3}{*}{$61-600$} & AA vs. PSPA & 0.5249 \\
\cline { 2 - 3 } & AA vs. NA & 0.1645 \\
\cline { 2 - 3 } & PSPA vs. NA & $\mathbf{0 . 0 4 2 2} *$ \\
\hline \multirow{3}{*}{$601-900$} & AA vs. PSPA & 0.4742 \\
\cline { 2 - 3 } & AA vs. NA & $\mathbf{0 . 0 4 2 2} *$ \\
\cline { 2 - 3 } & PSPA vs. NA & $\mathbf{0 . 0 2 7 5}$ \\
\hline \multirow{3}{*}{$901-1200$} & AA vs. PSPA & 0.615 \\
\cline { 2 - 3 } & AA vs. NA & $\mathbf{0 . 0 4 5} *$ \\
\cline { 2 - 3 } & PSPA vs. NA & 0.1199 \\
\hline
\end{tabular}




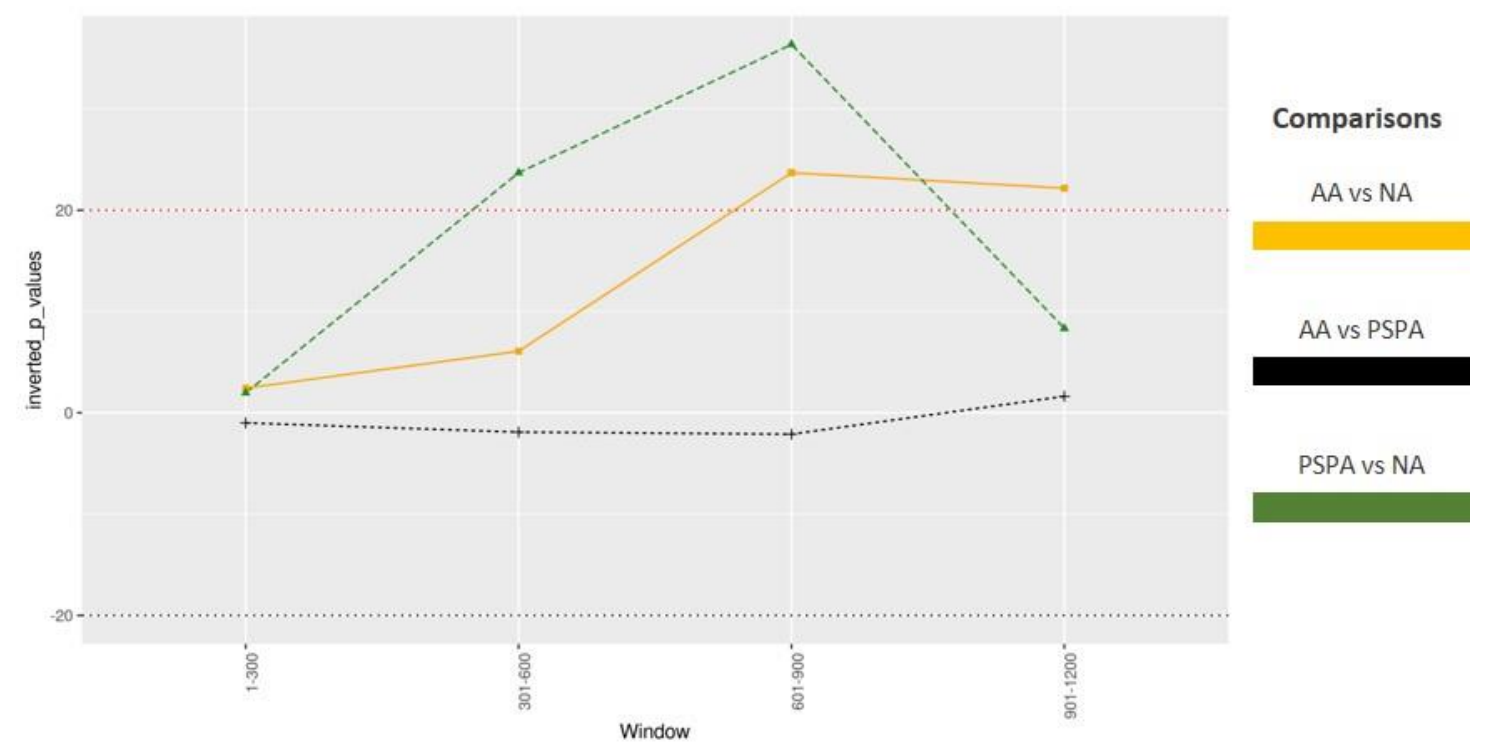

Figure 4. Inverted p values for the results of the different comparisons. The red dotted line at 20 (= 1/.05) corresponds to an $\alpha$ of .05. (AA= Asserted Action; PSPA= Presupposed Action; NA= NonAction).

\section{Discussion}

The first experiment addresses the question of whether true but possibly backgrounded action-related information activates motor brain structures. If presuppositions are considered as true by default, it seems that they should trigger a motor response. However, if presuppositions are backgrounded information, they might not elicit the same response compared to simple assertions. Our results reveal that Presupposed Action constructions elicit an increase in grip force. More precisely, grip force in the Presupposed Action condition is significantly higher than in the Non-Action condition and does not differ from the grip force in the Asserted Action condition.

Previous research has shown that language-induced motor activation is not triggered by the presence of an action verb per se but depends on contextual factors - cf. the interpretation of metaphors and idioms, the presence of a negation operator or of a volitional verb. More precisely, negative operators (Aravena et al., 2012; Tettamanti et al., 2008) and volitional contexts neutralize such activation (Aravena et al., 2014; Zwaan et al., 2010). Furthermore, discourse properties - such as the layering of information of what is said and what is implicated - also have an impact on the involved motor structures (van Ackeren et al., 2012). The present study extends these findings to the presupposition triggered by factive verbs. 
In a sentence like Paul knows that Mary ties her shoes, there is no previous context that entails or allows one to infer that Mary ties her shoes. One might conclude that we face a typical case of accommodation, where a presupposition, not being present in the context, has to be added to the belief set of some cognitive agent. Some studies show that processing accommodated presuppositions comes with a transient processing cost (EEG study by Domaneschi et al., 2018; Masia et al., 2017; self-paced reading study by Tiemann et al., 2011; Domaneschi \& Di Paolo, 2017; eye-tracking study by Tiemann \& Schwarz, 2012). Since we used decontextualized sentences, accommodating the presupposition could thus have either weakened or delayed the onset of the grip force effects. However, the results show no trace of such a difference. Actually, the increase of grip force is earlier and stronger for the Presupposed Action condition. This observation supports two possible conclusions. Decontextualized factive sentences might give rise to accommodation and the grip force technique be not sensitive to the accommodation status. Another possibility is that there is no accommodation proper because the factive verb, which occurs before the action-related verb phrase provides a cue to truth-conditional status and creates an expectation that the proposition expressed by the complement clause (Mary ties her shoes) is true without having to retrieve it from the context.

The present setting does not offer a way to arbitrate between these two options. However, under both perspectives, the experimental results support the view that speaker's commitment is a relevant factor. When a speaker uses a presupposition, he presents himself as accepting it as true (see note 1 in the introduction). When the addressee has no particular reason to question the beliefs of the speaker in terms of honesty or competence, she takes them for granted. In terms of situation model, this is equivalent to saying that, based on speaker's commitment, the addressee includes the presupposed proposition in her situation model in a way similar to a simple assertion. To ensure that the observed increase in grip force relates to the fact that the hand-related action verb occurs in the complement of a factive verb that guarantees its truth (e.g. know), we designed a second experiment where we replaced factive verbs with non-factive verbs such as believe or think. If our hypothesis is correct, this manipulation should weaken or neutralize the motor effect. 
Note that this second experiment serves also to control for the fact that the sentences in our three experimental conditions differ on several dimensions. For instance, as evident from Table 2, the sentence for Asserted Action sometimes contains two action words (leaving and tying) whereas the Presupposed Action condition contains only one (tying). Moreover, in the Asserted Action condition, the two events are ordered in time (first tying, then leaving) but, in the Presupposed Action sentence, the events of seeing and tying are happening at the same time and, in the Non-Action condition, the event (dinner) is implied to take place in the future. Note also that the number of persons in the sentences differ. In theory, all these variables could affect the results in unpredictable ways. However, if changing one single word, for instance the factive verb see (Experiment 1) into the non-factive verb imagine (Experiment 2), changes the relative pattern of results between the three conditions, we can attribute this change to the distinct status of factives and non-factives.

A reviewer remarks that it would have been more useful to keep the know (Experiment 1) and believe (Experiment 2) stimuli in a unique experiment, rather than to distribute them over two different experiments. Although we agree in principle, we think that the present design is less risky for two reasons.

First, the semantic and pragmatic properties of belief sentences are complex. They come with what is called a weak implicature, a disjunctive inference that addresses tend to draw, even it is not part of the literal content. For a sentence like Daniel believes that Ines ties her shoes, the weak/disjunctive implicature is that the speaker either believes that Ines does not tie her shoes or has no opinion about that ${ }^{9}$. Belief sentences are also somehow biased toward positive alternatives. To see what it means, consider (15) and (16).

15. Daniel believes that Ines ties her shoes, but he is wrong. $(\sqrt{ })$

16. Daniel believes that Ines ties her shoes, but he is right. (??)

The contrast relation conveyed by but makes sense only if the first sentence makes the positive alternative (Ines ties her shoes) more salient than the negative one (she does not), exactly as the symmetric operator doubt makes the negative alternative more salient, see 17 and 18.

\footnotetext{
${ }^{9}$ The corresponding strong implicature is the first term of the disjunction, namely that the speaker believes that Ines does not tie her shoes.
} 
17. Daniel doubts that Ines ties hers shoes, but he is wrong. $(\sqrt{ })$

18. Daniel doubts that Ines ties hers shoes, but he is right. (??)

Given the two properties of weak implicature and positive bias, it is difficult to control for possible effects of contrast between know and belief sentences when they coexist in the same experiment. For instance, it is possible that participants are more receptive to the weak implicature in a contrast knowbelieve setting and/or less receptive to the salience asymmetry than they would normally be.

Second, what we are primarily interested in is how much Presupposed and Non-Presupposed Action conditions align with the basic Asserted Action condition, which is our positive reference point. So, we would have to keep that condition anyway and the Asserted Action stimuli would use the same action verbs as the other two conditions. We cannot be sure that having three times the same verbs, even though it would be partly in different environments, would not induce some confusion for the participants. Disentangling these possible sources of problem, if possible at all, would take quite a few complementary experiments. The present design, even though it is not a within subject comparison, does not introduce possible parasitic effects.

\subsection{Experiment 2: Non-Factivity}

\section{Method}

Participants

34 participants ( 24 women; $19-35$ years old; $M_{\text {age }}=22.71, S D_{\text {age }}=4.03$ ) participated in this study. All were right-handed $\left(M_{\text {laterality }}=.95 ; S D_{\text {laterality }}=.15\right)$.

\section{Stimuli}

A total of 111 French sentences served as stimuli (see Supplementary Material). Thirty-seven target hand-related action verbs were embedded into Asserted Action and Non-Presupposed sentences. In addition, thirty-seven sentences containing asserted verbs were used. In contrast to experiment 1 , the sentences for Presupposed Action were replaced by Non-Presupposed ones (see Table 4). 8 distinct French non-factive verbs were used with respect to the factive stimuli: imaginer (to imagine, 5 times), dire (to say, 5 times), soupçonner (to suspect, 4 times), suspecter (to suspect, 5 times), penser (to think, 
5 times), croire (to believe, 5 times), supposer (to suppose, 4 times), and soutenir (to claim, 4 times).

All other selection and condition criteria used for experiment 1 also applied for this experiment.

The onsets of the critical verb and noun for the Asserted Action condition (Before leaving, Ines ties her shoes $)$ were on average $1406 \mathrm{~ms}(S D=205 \mathrm{~ms})$ and $1882 \mathrm{~ms}(S D=239 \mathrm{~ms})$ after the beginning of the sentence; for the Non-Presupposed Action (Daniel imagines that Anne ties her shoes.), they were on average $1290 \mathrm{~ms}(S D=187 \mathrm{~ms})$ and $1714 \mathrm{~ms}(S D=203 \mathrm{~ms})$; for the Non-Action condition (For his meal, Peter would like chicken. $)$ they were $1257 \mathrm{~ms}(S D=183 \mathrm{~ms})$ and $1734 \mathrm{~ms}(S D=218 \mathrm{~ms})$.

Table 4.

Example of Stimuli Used in Experiment 2 and their Approximate English Translation

\begin{tabular}{lll}
\hline $\begin{array}{l}\text { Condition } \\
\text { Asserted Action }\end{array}$ & $\begin{array}{l}\text { Sample stimulus } \\
\text { Avant de partir, Ines lace ses } \\
\text { chaussures. }\end{array}$ & $\begin{array}{l}\text { English approximate translation } \\
\text { Before leaving, Ines ties her shoes. }\end{array}$ \\
\hline Non-Presupposed Action & $\begin{array}{l}\text { Daniel imagine qu'Anne lace } \\
\text { ses chaussures. }\end{array}$ & $\begin{array}{l}\text { Daniel imagines that Anne ties her } \\
\text { shoes. }\end{array}$ \\
\hline Non-Action & $\begin{array}{l}\text { Pour le dîner, Pierre souhaite } \\
\text { du poulet. }\end{array}$ & For dinner, Peter would like chicken. \\
\hline
\end{tabular}

Equipment, data acquisition, and procedure were exactly the same as presented in Experiment 1.

\section{Data Analysis}

The data analysis was exactly the same as in Experiment 1.

4 participants were discarded because of negative drifts (participants 2, 16, 19, 31). Average response accuracy to the comprehension questions was $7.2(S D=1.05) .102$ items with a grip force below $150 \mathrm{mN}$ or above $200 \mathrm{mN}$ were eliminated (39 for Asserted Action, 34 for Non-Presupposed Action and 29 for Non-Action).

\section{Results}

The averaged results of grip force activation for all three conditions are depicted in Figure 5. 


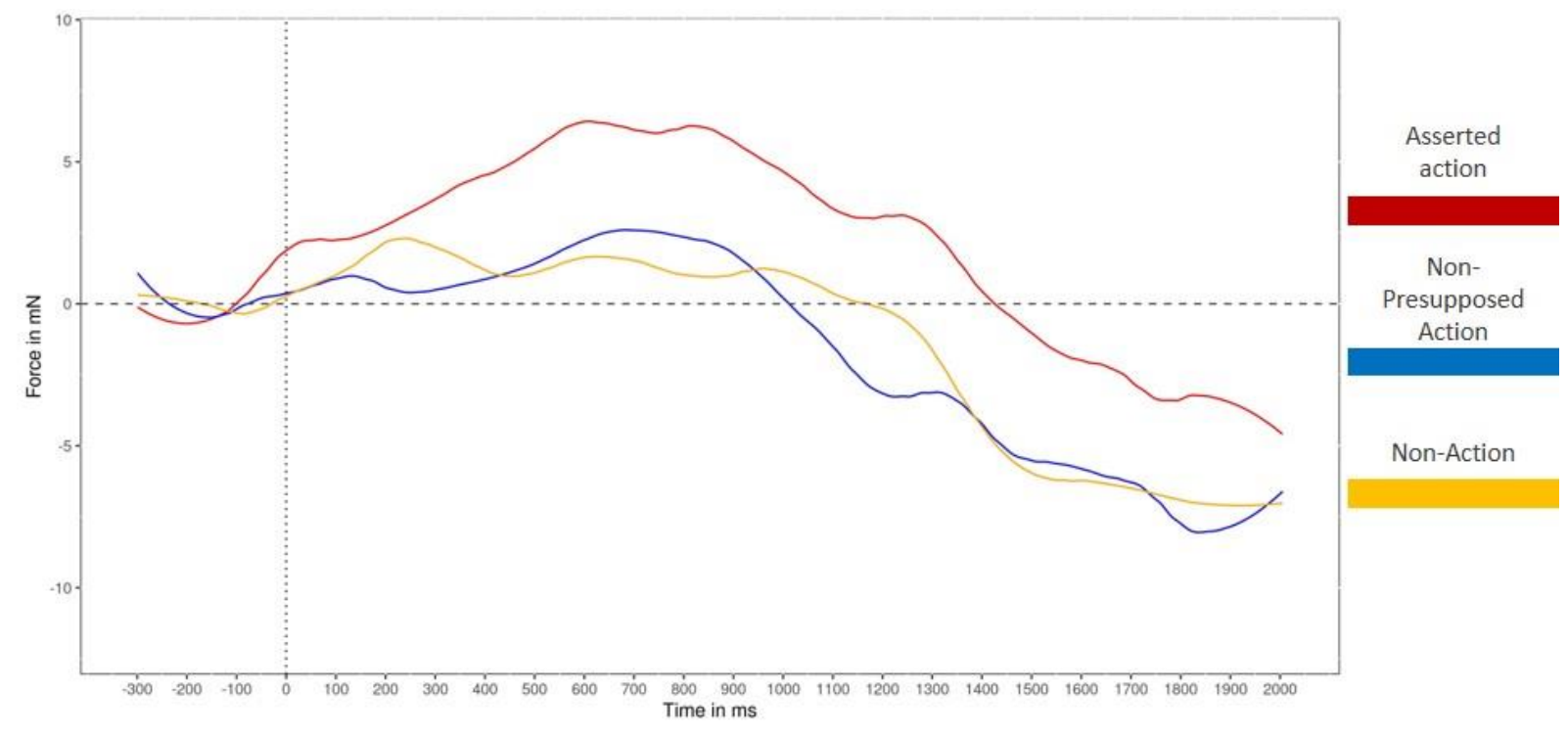

Figure 5. Results Experiment 2 - Modulation of grip force amplitude in the three experimental conditions as a function of time after the onset of the target word. Zero is the onset of the verb; baseline correction was applied over the $300 \mathrm{~ms}$ interval prior to verb onset.

The plot suggests that the Non-Presupposed Action and Non-Action conditions are close to each other and have lower amplitudes than the Asserted Action condition. The statistical results (Table 5) indicate that Asserted Action differs significantly from Non-Action over the 600-900 ms window (and over the 300-600 ms window). However, Non-Presupposed Action differs neither from Asserted Action nor from Non-Action in any of the time windows. Figure 6 summarizes the results in terms of inverted $p$ values.

\section{Table 5.}

$P$ values for Experiment 2. $*=p<.05 . A A=$ Asserted Action; NPSPA= Non-Presupposed Action; NA= Non-Action).

\begin{tabular}{|c|c|l|}
\hline Window & \multicolumn{1}{|c|}{ Comparison } & \multicolumn{1}{|c|}{ WT } \\
\hline \multirow{4}{*}{$1-300$} & AA vs. NPSPA & 0.1909 \\
\cline { 2 - 3 } & AA vs. NA & 0.3599 \\
\cline { 2 - 3 } & NPSPA vs. NA & 0.3492 \\
\hline \multirow{4}{*}{$301-600$} & AA vs. NPSPA & 0.0699 \\
\cline { 2 - 3 } & AA vs. NA & $\mathbf{0 . 0 4 9 7} *$ \\
\cline { 2 - 3 } & NPSPA vs. NA & 0.685 \\
\hline \multirow{3}{*}{$601-900$} & AA vs. NPSPA & 0.1094 \\
\cline { 2 - 3 } & AA vs. NA & $\mathbf{0 . 0 4 9 7} *$ \\
\cline { 2 - 3 } & NPSPA vs. NA & 0.8078 \\
\hline \multirow{3}{*}{$901-1200$} & AA vs. NPSPA & 0.428 \\
\cline { 2 - 3 } & AA vs. NA & 0.2534 \\
\cline { 2 - 3 } & NPSPA vs. NA & -0.6554 \\
\hline
\end{tabular}




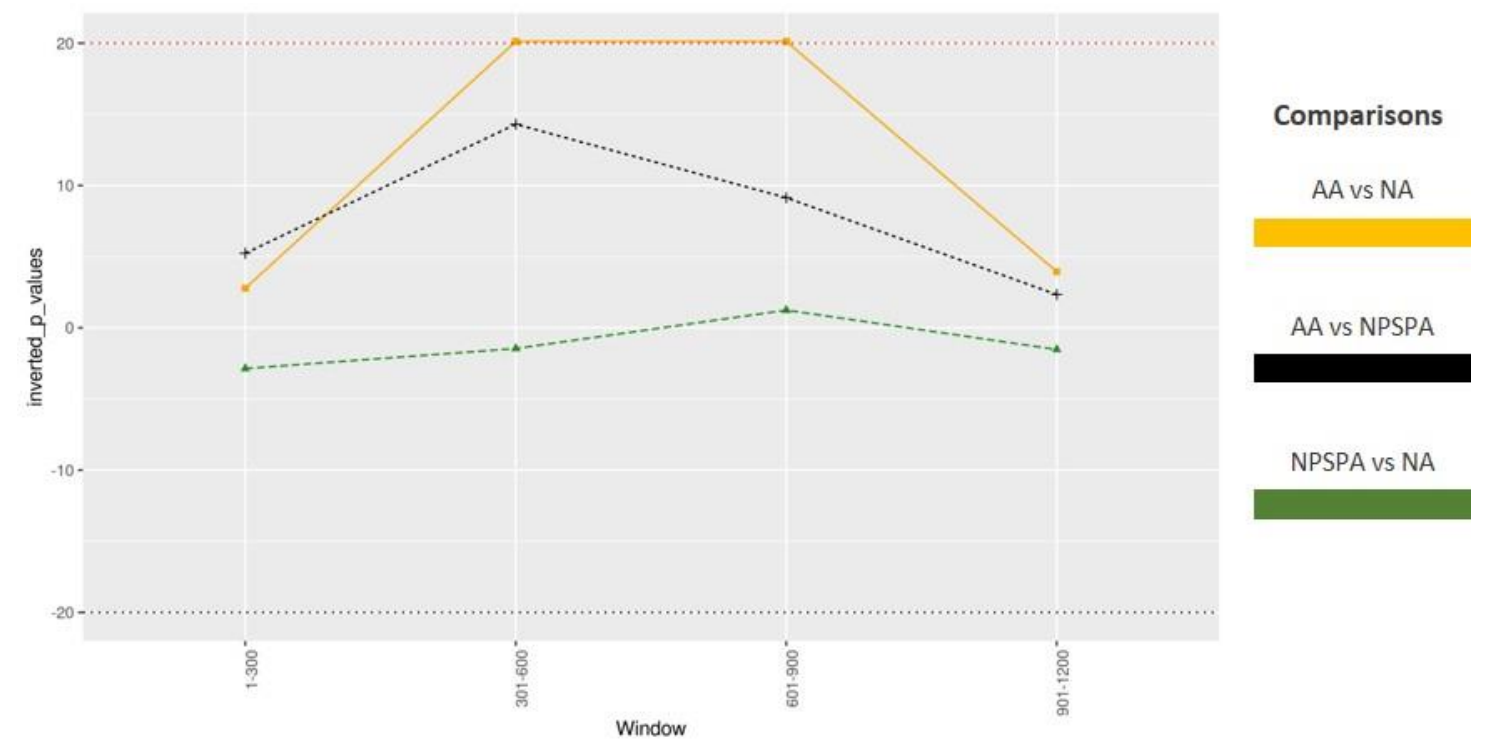

Figure 6. Inverted p values for the results of the different comparisons. The red dotted line at $20(=$ $1 / .05$ ) corresponds to an $\alpha$ of .05 . (AA= Asserted Action; NPSPA= Non-Presupposed Action; NA= Non-Action).

\section{Discussion}

The second experiment directly compares the action-related content of an assertion to the non-factive complement. Without prior context, the truth of the non-presupposed complement is unknown, that is, the information is neither true nor false. If, as we assume, the truth of the complement is a prerequisite for the recruitment of motor structures during the processing of action verbs, a weaker grip force level should be expected with non-factive complements. Our results show that the Asserted Action condition shows a significant increase in grip force when compared to the Non-Action condition. The NonPresupposed Action condition, does not differ significantly from the other two conditions.

Taken together, the results of experiments 1 and 2 suggest that the driving force behind the observed grip force modulations is the truth-conditional status of the action-related verb. In Experiment 1, the presupposition of a factive verb (e.g. know) is presented as true and the observed motor activation is not different from that of action-related verbs in simple assertive sentences. In Experiment 2, the presupposition is not presented as true, since it is embedded under a non-factive verb (e.g. believe), which does not presuppose the truth of the complement clause. In that case, the grip force does not reach the activation of Asserted-Action condition and, in fact, does not differ significantly from the Non-Action condition. Contrariwise, the grip force activation of the Presupposed-Action condition, as 
observed in Experience 1, is significantly larger than that of the Non-Action condition. Overall, independently of the fact that the Asserted Action, the Non-Action, and the Presupposed conditions differ on several dimensions (see the previous discussion section), the results of the two experiments together confirm that action-related verbs in themselves are not sufficient to generate a motor response and that the linguistic environment plays a crucial role (e.g. Cayol \& Nazir, 2020; Willems \& Casasanto, 2011).

The fact that the difference between the Non-Presupposed Action and the Asserted Action condition does not reach significance suggests that non-factive verbs might have an intermediate status between Non-Action and Asserted Action. On the one hand, they do not trigger a sufficient activation to depart significantly from non-action verbs. On the other hand, their distance to Asserted Action, over the time window of reference, is inferior to the distance from Non-Action to Asserted Action. This produces the kind of midway statistical situation we observe.

Our results of our first two experiments thus suggest that the presuppositional status in itself is not different from the asserted status for factive constructions, although differences between presupposed and asserted content have been observed when presuppositions are put into a discourse context (see, for instance, Masia et al., 2017, for definite versus indefinite descriptions and Simons, Beaver, Roberts, $\&$ Tonhauser, 2017, for factive constructions). A part of the theoretical literature on presuppositions assumes that, by default, presuppositions project, that is, are considered as true under certain operators like negation or interrogation. Accordingly, one might argue that they should trigger a motor activation under these operators. But, even though the truth-conditional status plays an important role, it is perhaps not sufficient to counteract the effect of operators which express opposition (negation) or uncertainty (interrogation). Admittedly, negation or interrogation do not bear directly on the presupposition. A sentence like Paul doesn't know that Mary writes the letter negates a certain knowledge of the agent Paul, but not the proposition that Mary writes the letter. Still, it might be the case that the negation affects the force of the presupposition. This can be done in at least two ways. First, negation could be parasitic on the presupposition, meaning that, although it does not combine with the presupposition, it could somehow 'taint' it. For instance, Aravena et al. (2012) suggest that negation could block the motor semantic representation of the negation target (for candidate neurophysiological grounds for this 
idea see de Vega et al., 2016; Papeo et al., 2016; Tettamanti et al., 2008). Second, it has been argued that, in some cases, negated factive verbs do not give rise to projection (Beaver, Roberts, Simons, \& Tonhauser, 2017; Simons et al., 2017). For instance, a sentence like Paul didn't observe that Mary was in the office can mean either that Mary was in the office and Paul did not notice her (the projection interpretation) or that Paul had no evidence that Mary was in the office (the non-projection interpretation). Adopting a projective reading, the perspective of the speaker outweighs the perspective of Paul (the agent). In contrast, a non-projective reading focuses on the perspective of the agent. Consequently, the latter interpretation should not elicit a grip force activation, whereas the former one should elicit one. The goal of our third experiment is to determine whether the negation operator influences the motor response in projective environments.

\subsection{Experiment 3: Projection}

\section{Method}

Participants

29 participants ( 15 women; $18-30$ years old; $\left.M_{\text {age }}=21.06, S D_{\text {age }}=3.22\right)$ participated in this study. All were right-handed $\left(M_{\text {laterality }}=.91 ; S D_{\text {laterality }}=.19\right)$.

\section{Stimuli}

A total of 111 French sentences served as stimuli. We decided to have a slightly more complex context clause for projective environments (a full sentence instead of a prepositional clause). This is motivated by the fact that, in some cases, having only a prepositional clause made the full target sentence somewhat unclear. For instance, In the launderette, Michael does not know that Cédric irons his shirt does not a priori make much sense if Cédric is not himself in the launderette. To solve this referential problem and help participants to attribute some relevance or plausibility to the action clause embedded under the projection environment (X does not know that), we replaced in the launderette by the sentence Cédric is in the launderette. Sentences for other conditions were modified accordingly. There are two possible problems with this choice. First, even though we chose very vague initial sentences we 
perhaps ran the risk of favoring the projective interpretation. Second, lengthening the stimuli when compared to the first two experiments might have some effects on processing.

Concerning the first possibility, we show below that, in the third experiment, the projection effect, if any, is late, moderate and restricted to a subset of participants, quite unlike the activation for factive sentences in the first experiment. Therefore, it is reasonable to conclude that motor activation under the Projection condition is not comparable to motor activation under the Presupposed Action condition of the first experiment. This conclusion is all the more plausible as the Presupposed Action condition could not benefit from the (hypothetical) effect of an initial sentence and had no advantage in this respect, contrary to the Projection condition. Moreover, it is not clear whether adding some linguistic material has a positive effect on motor response. We mentioned above the results by Raposo et al. (2009), who found a stronger motor activation for isolated verbs like grab than for the same verbs in a sentential context (The fruit cake was the last one so Claire grabbed it).

As for the possible effect of length, there is no correlation between length and grip force intensity in general: the average correlations for the Asserted Action condition are 0.17 for Experiment 1, -0.008 for Experiment 2 and 0.033 for Experiment 3. It is -0.022 for the late part of Experiment 3. It is -0.07 for the Presupposed Action condition of Experiment 1, 0.02 for the Projection condition of Experiment 3 and -0.08 for the late part of the same experiment.

Hand-related action verbs always appeared on the twelfth position $( \pm 2)$ of the sentence. 9 distinct French factive verbs were used under negation in the projective construction: voir (to see, 6 times), s'apercevoir (to realize, 4 times), entendre (to hear, 4 times), réaliser (to realize, 4 times), remarquer (to notice, 4 times), observer (to observe, 5 times), se rendre compte (to realize, once), savoir (to know, 5 times) and constater (witness, 4 times). A sample of stimuli is provided in Table 6. All previous selection and condition criteria used for experiments 1 and 2 also applied for this experiment.

The onsets of the critical verb and noun for the Asserted Action condition (Ines is leaving for work. Before going out, she ties her shoes $)$ were on average $3870 \mathrm{~ms}(S D=414 \mathrm{~ms})$ and $4305 \mathrm{~ms}(S D=$ $448 \mathrm{~ms}$ ) after the beginning of the sentence; for the Projected Action (Robert is busy in the living room. He does not see that Ghislaine ties her shoes), they were on average $3313 \mathrm{~ms}(S D=261 \mathrm{~ms})$ and 
$3701 \mathrm{~ms}(S D=281 \mathrm{~ms})$; for the Non-Action condition (Samuel greatly prefers poultry. For the dinner he would like chicken) they were $3501 \mathrm{~ms}(S D=302 \mathrm{~ms})$ and $3963 \mathrm{~ms}(S D=314 \mathrm{~ms})$.

Table 6.

Example of Stimuli Used in Experiment 3 and their Approximate English Translation Condition Sample stimulus English approximate translation

Asserted Action Ines va partir pour aller travailler.
Avant de sortir, elle lace ses chaussures.

\begin{tabular}{ll} 
& $\begin{array}{l}\text { Avant de sortir, elle lace ses chaus- } \\
\text { sures. }\end{array}$ \\
\hline Projected Action & $\begin{array}{l}\text { Robert est occupé dans le salon. Il } \\
\text { ne voit pas que Ghislaine lace ses } \\
\text { chaussures. }\end{array}$ \\
\hline
\end{tabular}
ne voit pas que Ghislaine lace ses Ines is leaving for work. Before

Non-Action Samuel préfère de beaucoup la volaille, Pour le dîner, il souhaite going out, she ties her shoes. du poulet.

\section{Measures and pre-tests}

To ascertain that the negation of a factive verb does, indeed, leave the factive complement unaffected, we first tested the projection of the factive complement in an online pilot study. Twenty-four French native speakers, aged from 21 to 48 years participated in this study $(M=31.66, S D=9.82)$. None of them followed a program in linguistics. Each participant saw five (randomly selected) of the thirtyseven projection sentences and ten filler sentences. After having read the sentence, the participant had to indicate whether the factive complement was true or false. In $84.2 \%$ of all questions, the factive complement was rated as true, whereas in $15.8 \%$ the factive complement was rated as false. This difference is significant $(z=10.59, p<.001, C I$ for correct answers $=70.10 \%-90.70 \%)$. In addition, the correct results also differ significantly from chance $(z=7.62, p<.0001)$. The results can be seen as evidence that, by default, the factive complement projects in our stimuli, that is, remains unaffected under a negative operator.

Equipment, data acquisition, and procedure were exactly the same as presented in experiment 1.

\section{Data Analysis}

The data analysis was exactly the same as in Experiment 1 . 
Participant 12 was removed because of recording problems. Furthermore, 6 participants were removed because they their grip force recordings showed a negative drift $(3,15,16,19,20,25)$. Two of these participants also had low response accuracy in the comprehension questions (i.e., 4). Mean response accuracy for the remaining participants was $7.1(\mathrm{SD}=1.37) .163$ items with a grip force below -150 $\mathrm{mN}$ or above $200 \mathrm{mN}$ were discarded (51 for Asserted Action, 53 for Projection and 59 for NonAction).

\section{Results}

The averaged results of grip force activation for all three conditions are depicted in Figure 7.

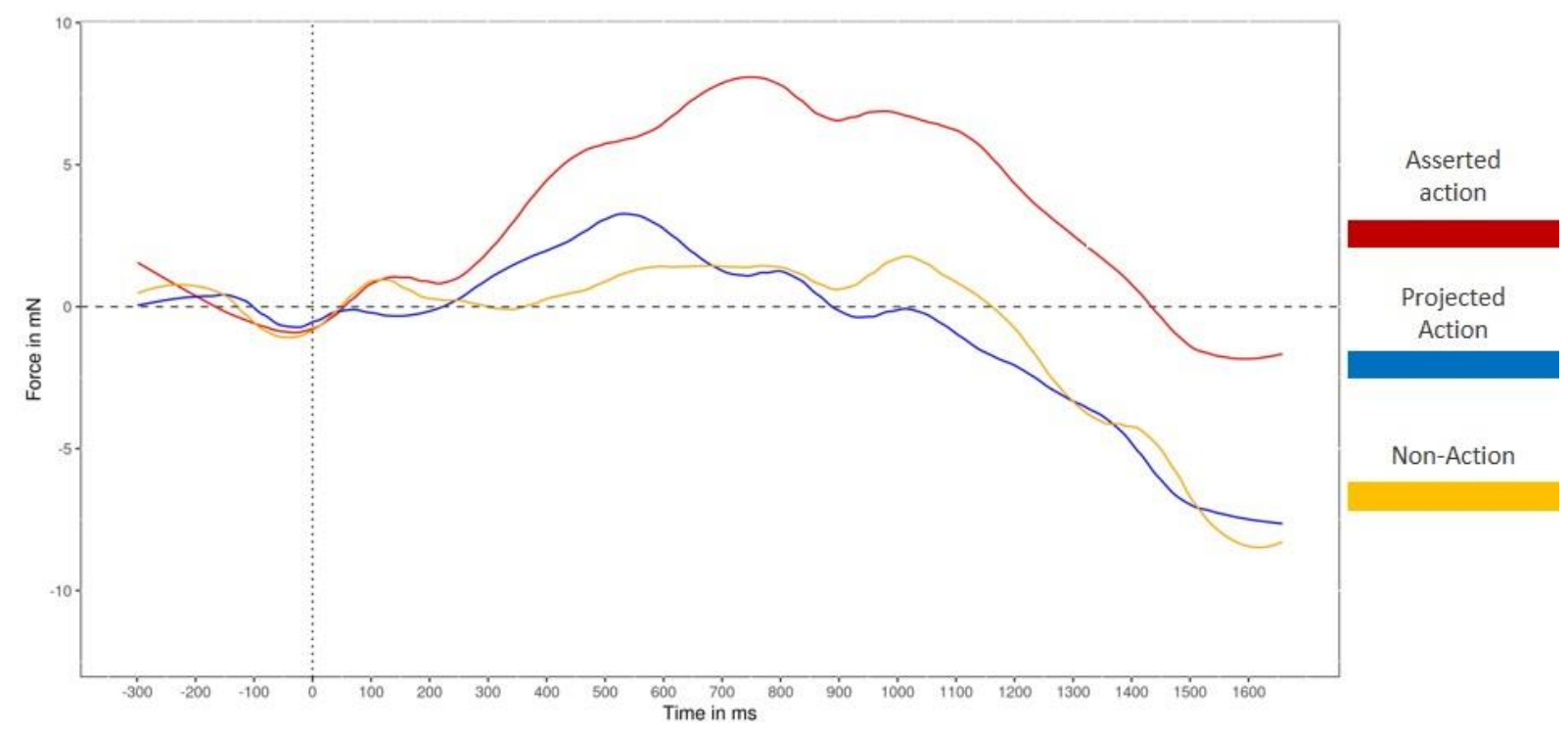

Figure 7. Modulation of grip force amplitude in the three experimental conditions as a function of time after the onset of the target word. Zero is the onset of the verb; baseline correction was applied over the $300 \mathrm{~ms}$ interval prior to verb onset.

The plot suggests that Projected Action and Non-Action are similar and both different from Asserted Action, which is confirmed by the statistical results reported in Table 7. In the 600-900 window, Asserted Action differs significantly from both Non-Action and Projected Action. Projected Action and Non-Action do not differ in any of the tested time windows. Figure 8 summarizes the results in terms of inverted $\mathrm{p}$ values.

Table 7.

$P$ values for Experiment 3. $*=p<.05 . A A=$ Asserted Action; $P A=$ Projected Action; NA= Non-Action.

\begin{tabular}{|c|c|c|}
\hline Window & Comparison & WT \\
\hline $1-300$ & AA vs. PA & 0.9746 \\
\hline
\end{tabular}




\begin{tabular}{|l|l|l|}
\hline \multirow{3}{*}{$301-600$} & AA vs. NA & 0.5028 \\
\cline { 2 - 3 } & PA vs. NA & 0.7502 \\
\hline \multirow{3}{*}{$601-900$} & AA vs. PA & 0.187 \\
\cline { 2 - 3 } & AA vs. NA & 0.0684 \\
\cline { 2 - 3 } & PA vs. NA & 0.5879 \\
\hline & AA vs. PA & $\mathbf{0 . 0 0 7 4}$ \\
\cline { 2 - 3 } & AA vs. NA & $\mathbf{0 . 0 1 0 3}$ \\
\cline { 2 - 3 } 901-1200 & PA vs. NA & 0.8237 \\
\hline & AA vs. PA & $\mathbf{0 . 0 4 2 5 ^ { * }}$ \\
\cline { 2 - 3 } & AA vs. NA & 0.1129 \\
\cline { 2 - 3 } & PA vs. NA & 0.924 \\
\hline
\end{tabular}

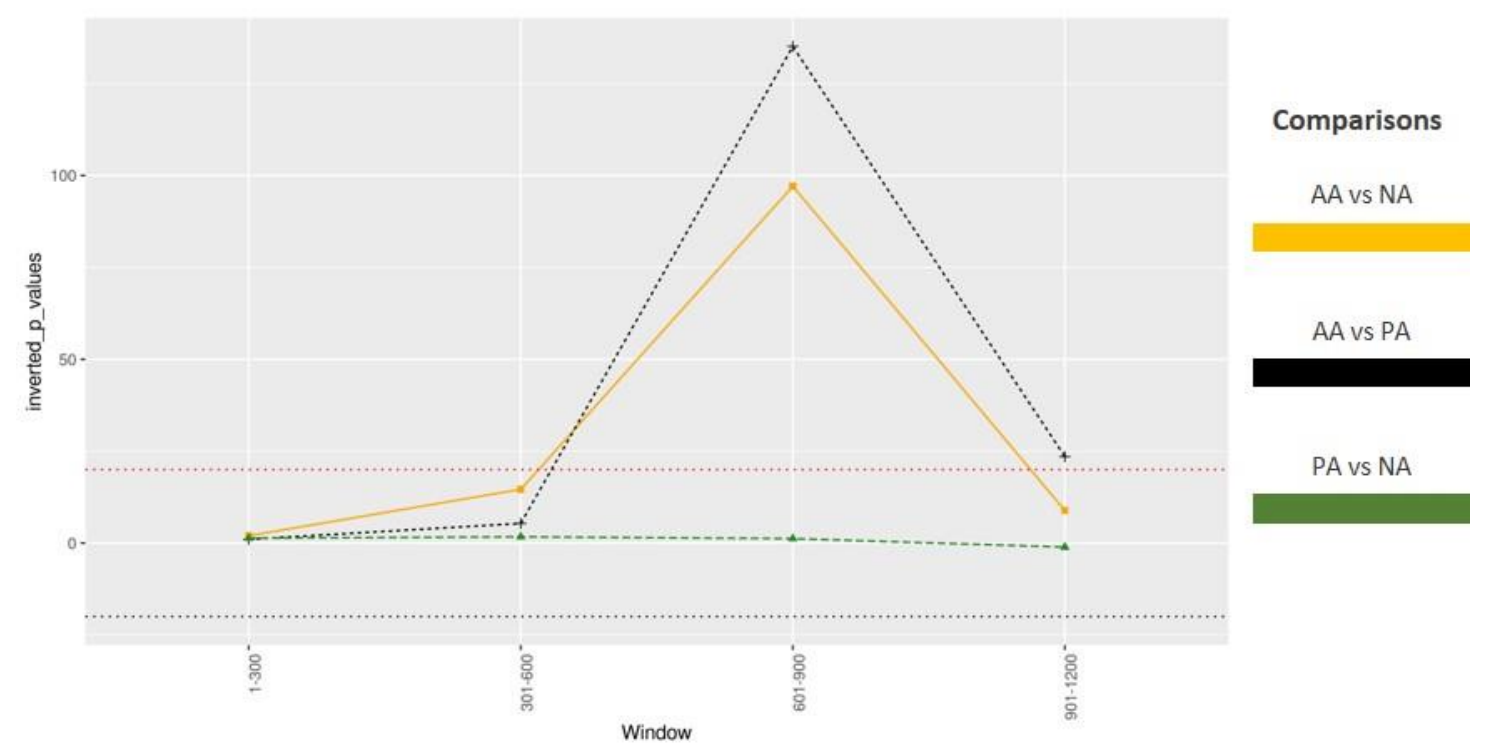

Figure 8. Inverted p values for the results of the different comparisons. The red dotted line at 20 (= $1 / .05)$ corresponds to an $\alpha$ of .05. ( $\mathrm{AA}=$ Asserted Action; $\mathrm{PA}=$ Projected Action; NA= Non-Action).

Based on these results, there is no evidence of a projection effect ${ }^{10}$. This might be due to the fact that projection does not take place or that it does not influence the grip response. Recall though that the linguistic literature suggests that projection is not an automatic or effortless process, in particular because it involves a combination of operators like negation or interrogation with the presupposition trigger itself (know, stop, etc.).

\footnotetext{
${ }^{10}$ In order to detect possible more fine-grained variations at later stages, we included a larger region, extending until $1000 \mathrm{~ms}$ after the 'latest' noun, that is the noun with the largest distance from the onset of its verb. Although there is an apparent rise of the curve for the Projection condition for half of the participants in the final part of the time series, the significance results for $300 \mathrm{~ms}$ windows do not offer any sufficient evidence for assuming that there is an activation increase.
} 


\section{Discussion}

The absence of a grip force modulation in the Projected Action condition could a priori be attributed to at least three possible scenarios. (i) the negation of the factive verb may have tainted a grip force activation of the true presupposed content. Such an explanation would be in line with research that suggests that negation does not give rise to a motor representation (e.g. Aravena et al., 2012; de Vega et al., 2016; Papeo et al., 2016; Tettamanti et al., 2008). (ii) It is also possible, as has been argued by Beaver et al. (2017) and Simons et al. (2017) that, in some cases, a projective interpretation of the presupposition of a negated factive verb construction does not arise. (iii) It is also possible that projection requires a cognitive effort which is time consuming, resulting in no motor response at all if it occurs after a 'critical' delay post target onset.

Whatever the case may be, the main take-away of Experiment 3 is that negative projection structures are not on par with factives or with non-factives. Like the Non-Presupposed Action condition in Experiment 2, the Projection condition is not distinct from the Non-Action condition. However, unlike the Non-Presupposed Action, Projection is in addition distinct from the Asserted Action condition. We return to the question of projection in the general discussion section.

\section{GENERAL DISCUSSION}

Using the grip force sensor technique (Aravena et al. 2012, 2014; Frak et al. 2010; Nazir et al. 2017), the present study is the first - to our knowledge - to investigate the involvement of the sensori-motor system in coded information layering. In Experiment 1, we compared asserted information with information embedded under a presuppositional factive verb construction. In Experiment 2, we extended our investigation to a non-factive verb construction. Lastly, we examined whether the projection behavior of a factive verb construction modulates sensori-motor activation under negation (Experiment 3). Our results indicate the following:

1. The presupposed factive complement triggers an increase in grip force. The presupposed content of factive verb constructions elicits a significantly higher grip force response than non- 
action verbs. The grip force response between the asserted and presupposed content does not differ significantly ${ }^{11}$.

2. The grip force activations recorded under the Non-Presupposed Action condition are not significantly different from those for the Non-Action condition or Asserted Action condition.

3. This contrast suggests that Non-Presupposed Action verbs (Experiment 2) and Presupposed Action verbs (Experiment 1) trigger different grip force activations.

4. When the factive verb is negated, the construction does not elicit a grip force response in the reference window. The grip force response of the action verb of negated factive verb constructions differs significantly from Asserted Action verbs but not from Non-Action verbs.

With sensori-motor activation as criterion, in Experiment 1 we tested the hypothesis that the backgrounded status of the factive complement engages motor brain structures differently compared to asserted content. This hypothesis was not confirmed. It is worth noting here that, based on descriptive linguistic analyses, Beaver (2010) and Simons et al. (2017) recently challenged the backgrounded status of factive complements altogether. Moreover, the corpus analysis by Spenader (2002) indicates that in more than fifty percent of the cases, the factive complement is introduced as new information. Results by Mazzarella, Reinecke, Mercier, and Noveck's (2018) on the impact of different levels of meaning on speaker commitment are also relevant. Using a selective trust paradigm, they show that trust scores between the asserting and presupposing speakers, in a condition where the presupposition conveys new information, as in the present study, do not differ significantly after the message is found unreliable. In the light of these works, it is thus not such a surprise that the factive complement also triggers a sensori-motor response. It is important to note that the grip force modulation differs signifi-

\footnotetext{
${ }^{11}$ To align the target position of the action verb in the asserted action condition (Before leaving, Ines ties her shoes) with the one of the presupposed action condition (Paul sees that Ines ties her shoes), we used a locative or temporal Preposition Phrase (PP) just before the asserted action clause. Given that the action clauses included the same action verbs, the only difference between the two mentioned condition is that the former contained this preposition phrase. Results by, for instance, Singh et al. (2016) revealed that plausibility impacts the processing between assertions and presuppositions when the latter must be accommodated. In their study, the authors report that the difference between assertions and presuppositions arises in implausible but not in plausible contexts. Given that our experimental stimuli were not influenced by prior sentences as this was the case in Singh et al.'s work, the only factor that may have had an influence was the prepositional phrase, If the PP would have made the action more plausible (or predictable), then the asserted action verb should have elicited a higher grip force response, However, this is not what our results indicate, since there is no significant difference between the asserted and presupposed action condition. Moreover, if there is any effect, it cannot explain the difference between the first two experiments: in both cases the stimuli for the Asserted Action condition are the same, but the contrast with the factive (know) vs. non-factive (believe) condition is not the same.
} 
cantly from the Non-Action condition. Combined with the result of our second experiment, which showed that the complement of a non-factive verb construction does not trigger a strong activation, it appears that the sensori-motor activation is modulated by the truth-conditional status of the action verb, not by the 'novelty' of the conveyed information. The difference between factives and nonfactives (know vs believe) is not the fact that the complement clause describes some novel event or not, but the fact that the complement is presented as true or not. In this respect, it should also be noted that the factive complement was not accented in the auditory material, which minimizes the possibility that this information represented the focus of the sentence. A follow-up study should investigate whether a focus manipulation, that is, accenting the asserted content while simultaneously de-accenting the presupposed content, affects sensori-motor correlates of the presupposed action. In conclusion, our findings extend the current knowledge about the contextual factors that modulate sensori-motor activity and demonstrate once more that language induced sensori-motor activation depends, in subtle ways, on contextual manipulations of lexical and discourse properties (e.g. van Ackeren et al. 2012; 2016; Egorova et al., 2014, 2016).

A reviewer remarks that situation models are also constructed "for events that are mentioned but do not take place", and that, as a result, the relation between grip force activation and situation models is perhaps not so clear. Indeed, some recent literature supports the idea that actions linguistically presented as non-occurring, as in negated or counterfactual sentences, are correlated with an activation of brain regions involved in action execution. Urrutia et al. (2012), using fMRI, studied brain activation for sentences like Since Pedro decided to paint the room, he is moving the sofa (factual) or If Pedro had decided to paint the room, he would have moved the sofa (counterfactual). They concluded that the parietal cortex hosts the computation of action representations irrespective of the reality status of the sentences. De Vega et al. (2014) reached a similar but even stronger conclusion after another fMRI study where they contrasted factual, negated and counterfactual sentences using action verbs. For all their conditions, they found a similar activation in parietal regions, which are also involved in action observation.

Admittedly, the interpretation of such results is not crystal-clear (see the Embodied or Conceptual Representations? section in de Vega et al., 2014). Assuming that the conclusion of the authors is cor- 
rect, that is, that some regions of the motor system are activated for negated and counterfactual sentences in a comparable way to factual assertions, how is it that we observe a variation with the grip force paradigm? There is at least one obvious possible explanation: the temporal resolution of fMRI and grip force is not the same. Urrutia et al. (2012) and de Vega et al. (2014) report a temporal resolution of $2000 \mathrm{~ms}$, which is quite inferior to the corticospinal excitability for hand muscles $(20 \mathrm{~ms}$ according to Rossini, Rossi, Pasqualetti, \& Tecchio, 1999). If temporal resolution is the main factor, one can conclude that the two findings are perfectly compatible: actual and non-actual situation models activate motor systems, but actual ones activate motor systems in a rapid and strong way, resulting in an "overflow of language-induced cortical motor activity to the muscles" (Cayol \& Nazir, 2020, p. 9). If there is some motor activation for counterfactuals, this could explain why we did not get a sharper difference between the Asserted Action and Non-Presupposed Action conditions in the second experiment. A sentence like Paul believes that Ines ties her shoes expresses the point of view of Paul, and the action clause is part of an alternative situation model, not unlike the alternative situation model of a counterfactual.

In philosophy of language and formal semantics, there is a rich tradition of modal analysis of propositions in terms of possible worlds (Portner, 2009). Although this framework is very abstract and not geared toward cognitive plausibility, it offers an interesting intuition: possible worlds can be anchored to a reference world. In everyday communication, this is the current world of our experience, in fiction this is the world of the fiction itself. These worlds are hyper-logical idealized situation models which provide the reality/fiction baseline in relation to which other worlds are located. We submit that, in the case of linguistic stimuli, strong grip force effects are observed when a participant listens to sentences which commit the speaker to a baseline situation model where a bodily action occurs. As we have explained in our answer to a comment by another reviewer (see note 1), commitment is the public conventional guarantee that a speaker offers as to her own beliefs. Of course, speakers may lie or joke, but, unless they provide evidence to the contrary, they are automatically perceived as sincere and serious and hearers react to the description they give of the baseline world. This does not entail that hearers necessarily believe what is said. Do the participants 'believe' the person who utters the various sentences in our experiments? We don't know and are not even sure that the question makes sense. 
The important point is that a bodily action is referred to in the baseline world, whether this world is considered to be identical to our real world or not. In belief sentences like Paul believes that Ines ties her shoes, we don't know whether the belief that Ines ties her shoes is true or false but we know that the speaker does not endorse its truth in the baseline world. What she is committed to is the truth of Paul believing that Ines ties her shoes. In contrast, with a factive verb like know, the speaker is committed to the truth of Ines ties her shoes in the baseline world, by the very definition of factive verbs.

The notion of speaker's commitment and of baseline world is perhaps also relevant to the symmetric findings in Experiments 1 and 3. As noted above, it could be argued that negation blocked or delayed a possible motor representation in Experiment 3. Given that (i) the results of our pre-test of the third experiment indicate that the factive complement was considered as true in $84.2 \%$ of all questions, (ii) in the experimental material, we took care of adding an introductory clause facilitating projection it is unlikely that negation automatically suppresses any representation of the event as true in the event model. In other terms, in a micro-text like Robert is busy in the drawing-room, he does not see that Ghislaine is tying her shoes, the negation of the second sentence can hardly be considered as preventing hearers to derive the proposition that Ghislaine is indeed tying her shoes and adding it to the current event model.

Yet, in view of the difference between Experiments 1 and 3, there is no question that negation affects the motor response. But how? Simons et al. (2017) and Beaver et al. (2017) have recently put forward a framework that challenges the conventional view of projection. According to the conventional view (e.g. Gazdar, 1979a, b; Heim, 1983, 1992), presuppositional behavior is considered as context independent, that is, it does not systematically interact with contextually available information. In this line, factive complements always project, irrespective of the presence of entailment-canceling operators, such as negation and interrogation, or of different contexts. In contrast, Beaver et al. (2017) clearly show that the projective readings of factive complements can be contextually suppressed as illustrated by one of their examples, where the critical sentence is underlined. In (19) there is no projection: A does not assume that the newer designs of nuclear plants are safer. Beaver et al. claim that non-projective interpretations arise when the speaker is not committed to the truth of the complement, as in (19). 
19. A: We have a major nuclear event going on in Japan, and it's far too early to claim that things are under control.

B: Well, again, these are older designs. The government assures us that the newer designs being proposed are much safer.

A: They don't know that. These were claimed to be the same-actually, the AP1000 that you were talking about building down in Vogtle, there are concerns right now about how well the containment will work.

According to Beaver et al.'s account, the projection criterion is not conventionally encoded per se, but interacts with the speaker's commitment to the truth of utterance. However, in decontextualized sentences, projection seems to be the default case, as evidenced by our off-line pretest on projection. As noted in the previous section, it is possible that projection is a relatively slow mechanism, exceeding the time bounds within which an action verb can trigger motor activation. It is also possible that the lack of activation observed in the second and third experiments derives in part from the noncoincidence between beliefs. In Paul knows that P, both the speaker and Paul (the agent) believe that P. In Paul believes that P, Paul believes that P but the speaker's belief state is unknown. In Paul doesn't know that $\mathrm{P}$, the speaker believes that $\mathrm{P}$ but Paul doesn't. The only case where we observed a similar activation to the simple Asserted Action is Experiment 1, where the speaker and the agent entertain the same belief with respect to P. However, the observations suggest that the status of Non-Presupposed condition and Projection condition are different, since unlike the latter, the former is not significantly different from Asserted Action. It is possible that, in Experiment 2, the fact that, under the perspective of the agent (in her baseline world), the proposition expressed through the action verb is true, has some activation effect, at least if it does not overtly conflict with the belief state of the speaker, which, in Experiment 2, is indeterminate. It is also possible that the mere mention of an action verb triggers some motor resonance, provided that the verb is not in the scope of negation. More work is needed to substantiate these various possible hypotheses.

The results of Experiment 1 and 2 are also relevant to the classic problem of compositionality, that is, the idea that the meaning of a sentence is a function of its grammatical structure and the meaning of its parts (Hinzen et al., 2012). This discussion is often centered on the question of whether the meaning of single words is computed first and then combined into a global interpretation, or whether a global interpretation is derived immediately or at some intermediate stage (see Degen, 2013 for a discussion of implicatures). Our results provide evidence against an account that considers that the domi- 
nant factor of motor activation is the lexical content of the action verb because the critical action verb does not provoke a grip force response in all conditions (e.g. no grip force increase in the nonpresupposed complement in Experiment 2 nor for the negated factive verb constructions of Experiment 3). In this respect, the first two experiments confirm the sensitivity of the grip force response to the construction of a plausible situation model based on the representation of events and all three experiments confirm the crucial impact of linguistic constructions on the motor response.

Thanks to the on-line nature of the grip force measure, the three experiments broaden our understanding of which linguistic environments elicit a grip force activation. More specifically, the use of this on-line measure allows to enhance our understanding of which linguistic environments recruit motor brain structures. In addition, it also provides new insights, which are not captured using an offline measure as our results on the pre-test of the third experiment reveal.

\section{Conclusion and Future Directions}

Over the last decades, the question of the role of the sensorimotor system in meaning representation has been vigorously debated by philosophers and neuroscientists. In a recent review, Meteyard et al. (2012) places the answers to this question on a continuum ranging from strong embodied positions (e.g. Gallese \& Lakoff, 2005; Glenberg \& Kaschak, 2003) to disembodied accounts (e.g. Mahon \& Caramazza, 2008).

Strong embodied accounts maintain the existence of a close link between linguistic meaning and sensorimotor structures and suggest that language processing depends on the recruitment of distributed networks of sensorimotor structures. Contrariwise, disembodied accounts defend the independence of linguistic meaning from sensorimotor structures by arguing that their recruitment is no evidence of an explanatory and causal link between language processing and sensorimotor structures.

There has been ample evidence that the truth may lie between these two opposite positions. A review by Willems and Casasanto (2011) points out that language-induced motor recruitment appears to be highly flexible and is moderated by situational context, be it linguistic or extra-linguistic (with regard to the linguistic context see, e.g., Aravena et al., 2012; 2014; Tettamanti et al., 2008, van Ackeren et al., 2012; with regard to the extra-linguistic context, see, e.g., Hoenig et al, 2008). In our studies, we 
investigated whether the factivity of a complement clause modulates the recruitment of sensorimotor areas. Our findings suggest that it does: factive action-related complements trigger a grip force activation whereas non-factive complements elicit a weaker response. Again, this challenges the claim that action word meaning automatically recruit motor semantic features and that sensorimotor processing is necessary for conceptual or language processing. Our results are thus compatible with an account that assumes context dependency of language-induced motor activity (see Cayol and Nazir, 2020). The activation of relevant action schemas, recruiting the same neural mechanisms as those active in overt behavior, selectively contributes to meaning representation as a function of the role the action plays in the overall discourse representation.

The current studies open up interesting directions for future research. While they demonstrate the selective involvement of the motor brain in the processing of hand-related action verbs, they leave open the question of what the role of such an activation is. Recent studies by Miller et al. (2018) investigated the sensitivity of ERP measures to hand and foot movements, as well as hand- and footassociated words. While they consistently found ERP differences for hand versus foot movements, they showed no evidence of a difference for hand- versus foot-associated words. The grip-force method has the potential to further contribute to this line of research by investigating the extent to which the sensorimotor activation it captures is univocally linked to the processing of hand-related semantic meanings (rather than reflecting a more general motor activation).

The implications of the studies presented in this paper go beyond the debate on embodiment, and directly address questions that are relevant to linguistics theories. In the present experiments, we focused on the distinction between factive (know) and non-factive verbs (believe). By contrasting these two conditions, our data suggest that the truth-conditional status of a clause (as determined by a factive verb) is a precondition for the recruitment of motor structures in language processes. These findings thus support a linguistic theoretical frame that considers the speaker's commitment to the truth of presupposed information as a central property of presuppositions (Peters, 2016), but they are also compatible with the idea that the agent's perspective has some impact during the recruitment of motor brain structures (Experiments 2 and 3). (Dis)Confirming the plausibility of this idea requires complementary experimental work. 
At this stage, the question naturally arises whether our observations are an effect of the particular structure of factive constructions or whether the conclusions they suggest extend to other presuppositional constructions. Recall that we chose factive constructions as a starting point for our experimental investigation because, in such constructions, the asserted content and the presupposition are expressed explicitly. This is not the case with other constructions. The present investigations must thus be extended to other presupposition triggers and we will briefly discuss some reasonable follow-ups in this direction. One important issue is that, with factives, the action-related verb occurs only in the presupposed part (the clausal complement), which prevents any direct comparison between asserted content and presupposed content in terms of motor response. As a result, what we have shown is that, when there is an action-related verb, the fact that it occurs in the presupposed part does not block or weaken the motor response. But what happens if asserted content and presupposed content have an opposite motor polarity (action vs. no action)?

Change-of-state verbs like begin or stop illustrate precisely this point. They assert the most recent event and presuppose a less recent state of affairs with an opposite polarity. For instance, Paul stops ironing his shirt asserts that Paul does not iron his shirt and presupposes that he has been doing so before. If the situation model contains all events referred to by the sentence, irrespective of their recency, it is possible that the two events (ironing vs. not ironing) cancel out and that no significant motor response is recorded. If the event of not-ironing is more salient, one would predict a null or weak motor response, and, correlatively, a stronger motor response for Paul begins ironing his shirt.

While change-of-state verbs are an interesting empirical family because they combine layers of information with opposite polarities, they are not the only ones with distinct presuppositional patterns within the heterogeneous class of presupposition triggers. Another major issue is the role of focus ${ }^{12}$, that is, this part of the sentence information which might be taken to address a question. For instance, with clefts such as It's Paul who irons his shirt, the presupposition is that someone irons a shirt and the asserted content is that it is Paul who does that. The sentence is most naturally viewed as a possible answer to a question like Who irons his shirt? So, the focus is on Paul, not on the presupposition, and

\footnotetext{
${ }^{12}$ The term focus is understood here as in linguistics (a sensible answer to a potential question) and is not to be confused with the meaning it has in Zwaan and Taylor's (2008) paper, mentioned in the introduction.
} 
one may wonder whether there is some effect on the motor response. If the latter is not significant, this would probably indicate that our hypothesis that the truth-conditional status of an action-related event is sufficient to trigger a motor response has to be amended. A similar question arises for exclusives (only, just), whose focus structure is a matter of debate (Beaver \& Clark, 2008). So, further work is needed to construct a more complete picture of the relations between motor response and coded semantic layering.

\section{Acknowledgments}

We would like to thank all the reviewers for their careful reading of our manuscript and their insightful comments and suggestions. Furthermore, we also thank Loriana Rizzo, Emilie Ganes, Hélène Boutaric, Caroline Masson and Julie Damour for assistance with stimuli preparation and stimuli recordings, and Anne Cheylus for programming the counterbalanced measures design and providing support for the analysis tool. We also thank Diana Mazzarella for comments on the first manuscript.

This research was supported by the French National Agency for Research (CogHuLiCe ANR 16CE28-0004) attributed to TN and SC, by a DAAD scholarship to RR, and by the French National Center for Scientific Research (CNRS). 


\section{Context Paragraph}

The present work brings together two different lines of research that are central to the work of the authors. On the one hand, the linguistic and philosophical analysis of the phenomenon of presupposition. On the other hand, the neurobiological investigation of language processing, with an emphasis on motor brain structures. These two lines of research converge around the issue of the context-sensitivity of language-induced sensori-motor activation. The question addressed by this paper is whether presuppositional contexts affect the activation of motor brain structures. The methodology employed is the gripforce method, which has been extensively developed at the Institut des Sciences Cognitives Marc Jeannerod in the last five years. 


\section{References}

Aravena, P., Courson, M., Frak, V., Cheylus, A., Paulignan, Y., Deprez, V., \& Nazir, T. (2014). Action relevance in linguistic context drives word-induced motor activity. Frontiers in Human Neuroscience, $8,163$.

Aravena, P., Delevoye-Turrell, Y., Deprez, V., Cheylus, A., Paulignan, Y., Frak, V., \& Nazir, T. (2012). Grip force reveals the context sensitivity of language-induced motor activity during "action words" processing: Evidence from sentential negation. PLoS One, 7(12), e50287.

Aziz-Zadeh, L., Wilson, S. M., Rizzolatti, G. \& Iacoboni, M. (2006). Congruent embodied representations for visually presented actions and linguistic phrases describing actions. Current Biology 16, $1818-1823$.

Barr, D. J., Levy, R., Scheepers, C., \& Tily, H. J. (2013). Random effects structure for confirmatory hypothesis testing: Keep it maximal. Journal of Memory and Language, 68(3), 255-278.

Bates, D., Maechler, M., Bolker, B., \& Walker, S.(2015). Fitting linear mixed-effects models using lme4. Journal of Statistical Software, 67, 1-48.

Beaver, D. I. (2001). Presupposition and assertion in dynamic semantics (Vol. 29). Stanford: CSLI publications.

Beaver, D. I. \& Clark, B. Z. (2008). Sense and Sensitivity. How Focus Determines Meaning. Chichester: Wiley-Blackwell.

Beaver, D. I., Geurts, B., \& Denlinger, K. (2021). Presupposition. In Zalta, E. N. (Ed.), The Stanford Encyclopedia of Philosophy, Stanford: Metaphysics Research Lab, Stanford University, https://plato.stanford.edu/archives/spr2021/entries/presupposition/.

Beaver, D. I., Roberts, C., Simons, M., \& Tonhauser, J. (2017). Questions Under Discussion: Where information structure meets projective content. Annual Review of Linguistics, 3, 265-284.

Boersma, P. \& Weenink, D. (2019). Praat: doing phonetics by computer [Computer program]. Version Praat 6.0.49, retrieved 19 January 2019 from http://www.praat.org/

Boulenger V, Roy A. C., Paulignan Y., Déprez V., Jeannerod M. \& Nazir, T. (2006). Cross-talk between language processes and overt motor behavior in the first $200 \mathrm{~ms}$ of processing. Journal of Cognitive Neuroscience, 18, 1607-1615. 
Boulenger, V., Hauk, O., \& Pulvermüller, F. (2008). Grasping ideas with the motor system: semantic somatotopy in idiom comprehension. Cerebral cortex, 19(8), 1905-1914.

Boulenger, V., Shtyrov, Y., \& Pulvermüller, F. (2012). When do you grasp the idea? MEG evidence for instantaneous idiom understanding. Neuroimage, 59(4), 3502-3513.

Brauer, M. \& Curtin, J.J. (2018). Linear mixed-effects models and the analysis of nonindependent data: A unified framework to analyze categorical and continuous independent variables that vary within-subjects and/or within-items. Psychological Methods, 23(3), 389-411.

Bulhof, J. \& Gimbel, S. (2001). Deep tautologies. Pragmatics and Cognition, 9(2), 279-291.

Cacciari, C., Bolognini, N., Senna, I., Pellicciari, M. C., Miniussi, C., \& Papagno, C. (2011). Literal, fictive and metaphorical action sentences preserve the action component of the verb: a TMS study. Brain and language, 119(3), 149-157.

Cayol, Z. \& Nazir, T. A. (2020). Why language processing recruits modality specific brain regions: It is not about understanding words, but about modelling situations. Journal of Cognition, 3(1), 35, $1-23$.

Chemla, E., \& Bott, L. (2013). Processing presuppositions: Dynamic semantics vs pragmatic enrichment. Language and cognitive processes, 28(3), 241-260.

Chierchia, G., \& McConnell-Ginet, S. (1990). Meaning and Grammar: An Introduction to Semantics. Cambridge (MA): MIT Press.

Claus, B. (2015). Verb gapping: An action-gap compatibility study. Acta Psychologica, 156, 104-113.

Degen, J. (2013). Alternatives in Pragmatic Reasoning. Ph.D. dissertation, University of Rochester.

Delevoye-Turrell, Y., \& Wing, A. (2005). Action and motor skills: Adaptive behaviour for intended goals. In Lamberts, K, \& Goldstone, R. (Eds.), Handbook of Cognition, London: Sage, 130-160.

Desai, R. H., Conant, L. L., Binder, J. R., Park, H., \& Seidenberg, M. S. (2013). A piece of the action: modulation of sensory-motor regions by action idioms and metaphors. NeuroImage, $83,862-$ 869. 
de Vega, M., León, I., Hernández, J. A., Valdés, M., Padrón, I. \& Ferstl, E. C. (2014). Action sentences activate sensory motor regions in the brain independently of their status of reality. Journal of Cognitive Neuroscience, 26(7), 1363-1376.

de Vega, M., Morera, Y., León, I., Beltrán, D., Casado, P., \& Martín-Loeches, M. (2016). Sentential negation might share neurophysiological mechanisms with action inhibition. Evidence from frontal theta rhythm. Journal of Neuroscience, 36(22), 6002-6010.

de Zubicaray, G., Arciuli, J., \& McMahon, K. (2013). Putting an "end" to the motor cortex representations of action words. Journal of Cognitive Neuroscience, 25(11), 1957-1974.

Domaneschi, F. (2016). Presuppositions and Cognitive Processes: Understanding the Information Taken for Granted. London: Palgrave Macmillan.

Domaneschi, F., Canal, P., Masia, V., Vallauri, E. L., \& Bambini, V. (2018). N400 and P600 modulation in presupposition accommodation: The effect of different trigger types. Journal of Neurolinguistics, 45, 13-35.

Domaneschi, F., \& Di Paola, S. (2017). The processing costs of presupposition accommodation. Journal of Psycholinguistic Research, 1-21.

Ducrot, O. (1972). Dire et ne pas Dire. Paris: Hermann.

Dudley, R., Orita, N., Hacquard, V., \& Lidz, J. (2015). Three-year-olds' understanding of know and think. In Experimental perspectives on presuppositions (pp. 241-262). Springer, Cham.

Egorova, N., Pulvermüller, F., \& Shtyrov, Y. (2014). Neural dynamics of speech act comprehension: an MEG study of naming and requesting. Brain Topography, 27(3), 375-392.

Egorova, N., Shtyrov, Y., \& Pulvermüller, F. (2016). Brain basis of communicative actions in language. NeuroImage, 125, 857-867.

Egré, P. (2008). Question-embedding and factivity. In Lihoreau, F. (Ed.), Knowledge and Questions, Grazer Philosophische Studien, vol. 77, Amsterdam: Rodopi, 85-125.

Frak, V., Nazir, T., Goyette, M., Cohen, H., \& Jeannerod, M. (2010). Grip force is part of the semantic representation of manual action verbs. PLoS One, 5(3), e9728. 
Friederici, A. D. (2002). Towards a neural basis of auditory sentence processing. Trends in cognitive sciences, 6(2), 78-84.

Gallese, V., \& Lakoff, G. (2005). The brain's concepts: The role of the sensory-motor system in conceptual knowledge. Cognitive neuropsychology, 22(3-4), 455-479.

Gazdar, G. (1979). A solution to the projection problem. In Oh, C.-K. \& Dinneen, D. A. (Eds.), Syntax and Semantics, vol. 11: Presupposition, New York: Academic Press, 57-89.

Geurts, B. (1999). Presuppositions and Pronouns. Amsterdam: Elsevier.

Gibbs, R. W. (2006). Metaphor interpretation as embodied simulation. Mind \& Language, 21(3), 434458.

Gibbs R. W., Lima, P. L. C., \& Francozo, E. (2004). Metaphor is grounded in embodied experience. Journal of pragmatics, 36(7), 1189-1210.

Grice, P. (1975). Logic and conversation. In Davidson, D. and Harman, G. (Eds), The Logic of Grammar, 64-75, Encino (CA): Dickenson.

Guijo-Rubio, D., Durán-Rosal, A. M., Gutiérrez, P. A., Troncoso, A., \& Hervás-Martínez, C. (2020). Time series clustering based on the characterisation of segment typologies. IEEE Transactions on Cybernetics, 1-14.

Hauk, O., Johnsrude, I., \& Pulvermüller, F. (2004). Somatotopic representation of action words in human motor and premotor cortex. Neuron, 41(2), 301-307.

Heim, I. (1983). On the projection problem for presuppositions, WCCFL 2, 114-125.

Heim, I. (1992). Presupposition projection and the semantics of attitude verb. Journal of Semantics, 9, $183-221$.

Hinzen, W., Machery, E., \& Werning M. (Eds.) (2012). The Oxford Handbook of Compositionality. Oxford: Oxford University Press.

Hoenig, K., Sim, E. J., Bochev, V., Herrnberger, B., \& Kiefer M. (2008) Conceptual flexibility in the human brain: dynamic recruitment of semantic maps from visual, action and motor-related areas. Journal of Cognitive Neuroscience, 20, 1799-1814.

Jeannerod, M. (1994). The representing brain: Neural correlates of motor intention and imagery. Behavioral and Brain sciences, 17(2), 187-202. 
Huette, S. (2016). Putting context into context: sources of context and a proposed mechanism for linguistic negation. Language, Cognition and Neuroscience, 31(8), 1000-1014.

Karttunen, L. (1974). Presupposition and linguistic context. Theoretical linguistics, 1(1-3), 181-194.

Kaup, B., Yaxley, R. H., Madden, C. J., Zwaan, R. A., \& Lüdtke, J. (2007). Experiential simulations of negated text information. Quarterly journal of experimental psychology, 60(7), 976-990.

Kiefer, M., \& Pulvermüller, F. (2012). Conceptual representations in mind and brain: Theoretical developments, current evidence and future directions. Cortex, 48(7), 805-825.

Kiparsky, P. \& Kiparsky, C. (1970). Fact. In M. Bierwisch \& K. Heidolph (Eds.), Progress in Linguistics, The Hague: Mouton, 143-173.

Kuhtz-Buschbeck, J. P., Ehrsson, H. H., \& Forssberg, H. (2001). Human brain activity in the control of fine static precision grip forces: an fMRI study. European Journal of Neuroscience, 14(2), 382-390.

Lauro, L. J. R., Mattavelli, G., Papagno, C., \& Tettamanti, M. (2013). She runs, the road runs, my mind runs, bad blood runs between us: Literal and figurative action verbs: An fMRI study. NeuroImage, $83,361-371$.

Levinson, S. C. (1983). Pragmatics. Cambridge: Cambridge University Press.

Lewis, D. (1979). Scorekeeping in a language game. Journal of philosophical logic, 8(1), 339-359.

Masia, V., Canal, P., Ricci, I., Vallauri, E. L., \& Bambini, V. (2017). Presupposition of new information as a pragmatic garden path: Evidence from Event-Related Brain Potentials. Journal of Neurolinguistics, 42, 31-48.

Matuschek, H., Kliegl, R., Vasishth, S., Baayen, H. \& Bates, D. (2017). Balancing type I error and power in linear mixed models. Journal of Memory and Language, 94, 305-315.

Miller, J., Brookie, K., Wales, S., Kaup, B., \& Wallace, S. (2018). Embodied cognition: Is activation of the motor cortex essential for understanding action verbs?. Journal of Experimental Psychology: Learning, Memory, and Cognition, 44, 335-370.

Moody, C. L., \& Gennari, S. P. (2010). Effects of implied physical effort in sensory-motor and prefrontal cortex during language comprehension. Neuroimage, 49(1), 782-793. 
Nagel, J. (2017). Factive and nonfactive mental state attribution. Mind \& Language, 32(5), 525-544.

Nazir, T. A., Hrycyk, L., Moreau, Q., Frak, V., Cheylus, A., Ott, L., ... \& Delevoye-Turrell, Y. (2017). A simple technique to study embodied language processes: the grip force sensor. Behavior research methods, 49(1), 61-73.

New, B., Pallier, C., Ferrand, L., \& Matos, R. (2001). Une base de données lexicales du français contemporain sur internet: LEXIQUETM/A lexical database for contemporary French: LEXIQUETM. L'année psychologique, 101(3), 447-462.

Oldfield, R.C. (1971). The assessment and analysis of handedness: The Edinburgh inventory. Neuropsychologia, 9(1), 97-113.

Peters, S. (2016). Speaker commitments: Presupposition. In Semantics and Linguistic Theory (Vol. 26, pp. 1083-1098).

Papeo, L., Hochmann, J. R., \& Battelli, L. (2016). The default computation of negated meanings. Journal of cognitive neuroscience, 28(12), 1980-1986.

Portner, P. (2009). Modality. Oxford: Oxford University Press.

Pulvermüller, F. (2005). Brain mechanisms linking language and action. Nature Reviews Neuroscience, 6(7), 576 .

Pulvermüller, F., Hauk, O., Nikulin, V. V., \& Ilmoniemi, R. J. (2005). Functional links between motor and language systems. European Journal of Neuroscience, 21(3), 793-797.

R Core Team (2019). R: A language and environment for statistical computing. R Foundation for Statistical Computing, Vienna, Austria. URL https://www.R-project.org/.

Radvansky, G. A., \& Zwaan, R.A. (2014). Event Cognition. New York: Oxford University Press.

Raposo, A., Moss, H. E., Stamatakis, E. A., \& Tyler, L. K. (2009). Modulation of motor and premotor cortices by actions, action words and action sentences. Neuropsychologia, 47(2), 388-396.

Reboul, A. (2017). Is implicit communication a way to escape epistemic vigilance?. In Assimakopoulos, S. (Ed.), Pragmatics at its Interfaces, Berlin: De Gruyter Mouton, 91-112. 
Romoli, J., Khan, M., Sudo, Y., \& Snedeker, J. (2015). Resolving temporary referential ambiguity using presupposed content. In Experimental perspectives on presuppositions (pp. 67-87). Springer, Cham.

Romoli, J., \& Schwarz, F. (2015). An experimental comparison between presuppositions and indirect scalar implicatures. In Schwarz, F. (Ed.), Experimental Perspectives on Presuppositions, Cham: Springer, 215-240.

Rossini, P. M., Rossi, S., Pasqualetti, P., \& Tecchio, F. (1999). Corticospinal excitability modulation to hand muscles during movement imagery. Cerebral cortex, 9(2), 161-167.

Schlenker, P. (2008). Be articulate: A pragmatic theory of presupposition projection. Theoretical Linguistics, 34(3), 157-212.

Schwarz, F. (2014). Presuppositions are fast, whether hard or soft-evidence from the visual world. In Snider, T., D’Antonio, S., \& Wiegand, M. (Eds.), Semantics and Linguistic Theory 24, LSA and CLC Publications, 1-22.

Schwarz, F. (2015). Introduction: Presuppositions in context-Theoretical issues and experimental perspectives. In Schwarz, F. (Ed.), Experimental Perspectives on Presuppositions, Cham: Springer, 1-37.

Schwarz, F. (2016). Experimental work in presupposition and presupposition projection. Annual review of linguistics, 2, 273-292.

Schwarz, F., \& Tiemann, S. (2012). Presupposition Processing-The Case of German wieder. In Logic, Language and Meaning (pp. 200-209). Springer, Berlin, Heidelberg.

Shetreet, E., Alexander, E. J., Romoli, J., Chierchia, G., \& Kuperberg, G. (2019). What we know about knowing: Presuppositions generated by factive verbs influence downstream neural processing. Cognition, 184, 96-106.

Simons, M., Beaver, D., Roberts, C., \& Tonhauser, J. (2017). The best question: Explaining the projection behavior of factives. Discourse Processes, 54(3), 187-206. 
Singmann, H \& Kelen, D. (2020). An introduction to mixed models for experimental psychology. In Spieler, D. \& Schumacher, E. (Eds.), New Methods in Cognitive Psychology, London: Routledge, 4-31.

Spenader, J. (2002). Presuppositions in spoken discourse (Doctoral Dissertation, Stockholm University, Stockholm, Sweden). Retrieved from: https://www.ai.rug.nl/ spenader/public_docs/SpenaderDissertation.pdf

Stalnaker, R. (1974). Pragmatic presuppositions. In M. K. Munitz \& P. Unger (Eds.), Semantics and Philosophy, New York: New York University Press, 197-213.

Stalnaker, R. (2002). Common ground. Linguistics and Philosophy, 25(5-6), 701-721.

Stegmann, G., Jacobucci, R., Harring, J. R., \& Grimm, K. J. (2017). Non-linear mixed-effects modeling programs in R. Structural Equation Modeling: A Multidisciplinary Journal, 25(1), 160-165.

Stroup, W. W. (2012). Generalized Linear Mixed Models: Modern Concepts, Methods and Applications. CRC Press, Boca Raton.

Taylor, L. J., \& Zwaan, R. A. (2008). Motor resonance and linguistic focus. Quarterly Journal of Experimental Psychology, 61(6), 896-904.

Tettamanti, M., Buccino, G., Saccuman, M. C., Gallese, V., Danna, M., Scifo, P., ... \& Perani, D. (2005). Listening to action-related sentences activates fronto-parietal motor circuits. Journal of cognitive neuroscience, 17(2), 273-281.

Tettamanti, M., Manenti, R., Della Rosa, P. A., Falini, A., Perani, D., Cappa, S. F., \& Moro, A. (2008). Negation in the brain: Modulating action representations. Neuroimage, 43(2), 358-367.

Tian, Y., Ferguson, H., \& Breheny, R. (2016). Processing negation without context-why and when we represent the positive argument. Language, Cognition and Neuroscience, 31(5), 683-698.

Tiemann, S., Schmid, M., Bade, N., Rolke, B., Hertrich, I., Ackermann, H., ... \& Beck, S. (2011). Psycholinguistic evidence for presuppositions: On-line and off-line data. In Proceedings of sinn \& bedeutung (Vol. 15, pp. 581-597). Saarland University Press Saarbrücken.

Urrutia, M., Gennari, S. P. \& de Vega, M. (2012). Counterfactuals in action: An fMRI study of counterfactual sentences describing physical effort. Neuropsychologia, 50, 3663-3672. 
van Ackeren, M. J., Casasanto, D., Bekkering, H., Hagoort, P., \& Rueschemeyer, S. A. (2012). Pragmatics in action: indirect requests engage theory of mind areas and the cortical motor network. Journal of Cognitive Neuroscience, 24(11), 2237-2247.

van Ackeren, M. J., Smaragdi, A., \& Rueschemeyer, S. A. (2016). Neuronal interactions between mentalising and action systems during indirect request processing. Social cognitive and affective neuroscience, 11(9), 1402-1410.

Ward NS, Newton JM, Swayne OB, Lee L, Frackowiak RS, Thompson AJ, Greenwood RJ, Rothwell JC. The relationship between brain activity and peak grip force is modulated by corticospinal system integrity after subcortical stroke. Eur J Neurosci. 2007 Mar;25(6):1865-73.

Wickham, H. (2016). ggplot2: Elegant Graphics for Data Analysis. Springer Verlag.

Wickham H. (2019). forcats: tools for working with categorical variables (factors). R package version 0.4.0 https://CRAN.R-project.org/package=forcats.

Willems, R. M., \& Casasanto, D. (2011). Flexibility in embodied language understanding. Frontiers in Psychology, 2, 116.

Winterstein, G. (2013). The independence of quantity implicatures and contrast relations. Lingua, 132, $67-84$

Zwaan, R. A., \& Radvansky, G. A. (1998). Situation models in language comprehension and memory. Psychological bulletin, 123(2), 162.

Zwaan, R. A., Taylor, L. J., \& De Boer, M. (2010). Motor resonance as a function of narrative time: Further tests of the linguistic focus hypothesis. Brain and Language, 112(3), 143-149. 